\title{
Bauxitas do nordeste do Amazonas
}

\author{
Sanclever Freire Peixoto ${ }^{1} \&$ Adriana Maria Coimbra Horbe ${ }^{2}$
}

\begin{abstract}
Resumo Este trabalho discute os perfis com crosta bauxítica desenvolvidos sobre rochas ígneas e sedimentares do NE do estado do Amazonas. Os resultados estruturais, texturais, mineralógicos e químicos apontam algumas diferenças entre eles, as quais refletem principalmente a natureza de suas rochas-mãe. A crosta bauxítica dos perfis 1 (rochas vulcânicas) e 2 (graníticas) é mais espessa que no perfil 3 (sedimentares), apresenta maior variedade de fácies (maciça, protonodular, nodular e pisolítica) e se desenvolveu imediatamente acima do saprólito. Por outro lado, o perfil 3 possui espesso horizonte mosqueado, crosta ferruginosa bem desenvolvida e crosta bauxítica incipiente. A análise de componentes principais (ACP) definiu as seguintes associações geoquímicas: (1) $\mathrm{SiO} 2, \mathrm{~A} 12 \mathrm{O} 3, \mathrm{~K} 2 \mathrm{O}$, Ba, Sr e ETRL, onde $\mathrm{SiO} 2$ predomina no saprólito e mosqueado do perfil 3 como quartzo, Al2O3 na crosta bauxítica (maciça e pisolítica) e nos fragmentos dos perfis 1 e 2 como gibbsita e secundariamente na caulinita, enquanto $\mathrm{Ba}$, Sr e ETRL destacam-se no saprólito dos perfis 1 e 3, associados a feldspato, illita e muscovita; (2) V, Pb, Fe2O3 e As estão concentrados, principalmente na crosta ferruginosa dos três perfis e seus fragmentos ricos em óxi-hidróxidos de ferro (hematita e goethita), enquanto (3) Ga, Th, $\mathrm{Ta}, \mathrm{Sn}, \mathrm{Nb}, \mathrm{Hf}, \mathrm{Zr}, \mathrm{Y}, \mathrm{TiO} 2$ e ETRP predominam na matriz do desmantelado e no solo dos perfis 1 e 2, associados aos resistatos (zircão, columbita, thorita, xenotima, etc) ou como anatásio (TiO2). Os resultados indicam qualidade industrial para os horizontes bauxíticos da mina do Pitinga (perfis 1 e 2) e são equivalentes aos das bauxitas de outras regiões da Amazônia. Os três perfis foram interpretados como produto de alteração in situ, e apesar de resultarem do intemperismo polifásico atuante em toda a Amazônia desde o Cretáceo Superior, a ausência de horizonte mosqueado nos perfis 1 e 2 em relação aos que ocorrem sobre as vulcânicas mais a sul da área sinaliza variações regionais nas condições de lixiviação. Isto justifica também o não desenvolvimento de horizontes bauxíticos em outras áreas e a bauxita incipiente sobre a Formação Prosperança.
\end{abstract}

Palavras-chaves: Rochas ígneas, Amazônia, intemperismo, composição química, componentes principais, associações geoquímicas.

\begin{abstract}
Bauxites of the northeastern of Amazonas. This paper discuss the profiles with bauxitic crust formed from igneous and siliciclastic rocks of the northeastern part of the Amazonas. The structural, textural, mineralogic and chemical results show some differences among them, which reflect mainly in the parent rock nature. The bauxitic crust from profiles 1 (volcanic rocks) and 2 (granitic) is thicker than in the profile 3 (sedimentary), shows greater range of facies (massive, pronodular, nodular and pisolitic) and developed right over the saprolite. On the other hand, the profile 3 thick mottled horizon, ferruginous crust well developed and bauxitic crust not well formed. The principal component analysis (PCA) for elements and samples defined the following geochemical associations: (1) $\mathrm{SiO} 2, \mathrm{Al} 2 \mathrm{O} 3, \mathrm{~K} 2 \mathrm{O}, \mathrm{Ba}, \mathrm{Sr}$ e LREE, where $\mathrm{SiO} 2$ predominate in the saprolite and mottled from profile 3 in the form of quartz, $\mathrm{Al} 2 \mathrm{O} 3$ in the bauxitic crust (massive and pisolitic) and the fragments from the profiles 1 and 2 in the form of gibbsite and secondly in kaolinite, whereas $\mathrm{Ba}, \mathrm{Sr}$ e LREE occur principally in the saprolite from profiles 1 e 3, associated to feldspar, illite and muscovite; (2) $\mathrm{V}, \mathrm{Pb}, \mathrm{Fe} 2 \mathrm{O} 3$ and $\mathrm{As}$ are concentrated mainly in the ferruginous crust of the three profiles and their fragments rich in Fe oxy-hydroxides (hematite and goethite), whereas (3) Ga, Th, Ta, Sn, Nb, Hf, Zr, Y, TiO2 e HREE predominate in the matrix of the concretionary horizon and in the soil of profiles 1 and 2, assotiated with the resistant (zircon, columbite, thorite, xenotime, etc) or in the form of anatase (TiO2). The results indicate industrial quality for the bauxitic horizons of mine Pitinga (profiles 1 and 2) and are equivalent of the bauxites extracted from other Amazon regions. The three profiles were interpreted as the result of weathering in situ, and despite their resulting from poliphasic weathering acting in the whole Amazon region since Upper Cretaceous, the absence of mottled horizon in the profiles 1 and 2 in relation to the occurrence over the volcanic rocks further south suggests regional variations in the leaching conditions. This also justifies the absence of bauxitic horizon in other areas and the small development over Prosperança Formation.
\end{abstract}

Keywords: Igneous rock, Amazônia, weathering, chemical composition, principal component analysis, geochemical associations.

1 - Universidade Federal do Amazonas, Programa de Pós-Graduação em Geociências, Departamento de Geociências, Manaus (AM),

Brasil. E-mail:sancleverp@yahoo.com.br

2 - Universidade Federal do Amazonas, Departamento de Geociências, Manaus (AM), Brasil. E-mail: ahorbe@ufam.edu.br 
INTRODUÇÃO O clima sazonal quente e úmido da Amazônia propiciou intenso intemperismo e o conseqüente desenvolvimento de amplo espectro de perfis de alteração durante o Cenozóico (Dennen \& Norton 1977, Grubb 1979, Kronberg et al. 1979 e 1982, Costa 1991, Angélica \& Costa 1991 e 1993, Costa et al. 1993, Costa \& Araújo 1996, Costa 1997, Fernandes Filho et al. 1997, Horbe \& Costa 1999, Costa et al. 1999) e, conseqüentemente de bauxita (Boulangé \& Carvalho 1997, Lucas 1997, Kotschoubey et al. 2005a, 2005b e 1997). Os grandes depósitos de bauxita da Amazônia (Paragominas, Juruti, Trombetas e Almerim) estão associados às rochas sedimentares das Formações Itapecuru e Alter do Chão, bacias do Parnaíba e Amazonas, respectivamente, entretanto rochas ígneas e metamórficas também formam jazidas no sudeste do Brasil como as de Ouro Preto, Poços de Caldas, Cataguazes, Miraí (Guimarães \& Coelho 1945, Lopes \& Carvalho 1990, Schulman et al. 1997, Beissner et al. 1997) e na África, Venezuela e Austrália (Sadlier \& Gilkes 1976, Davy 1979, Anand \& Gilkes 1987, Hickman et al. 1992, Soler \& Lasaga 2000, Anand \& Butt 2003, Mutakyahwa et al. 2003).

No nordeste do Amazonas, sobre as rochas sedimentares das Formações Nhamundá e Alter do Chão, ocorre bauxita, mas é esporádica e em horizontes pouco desenvolvidos (Horbe et al. 2001). Entretanto, sobre as vulcânicas e granitos do Grupo Uatumã, Costa et al. (1988) relata a primeira ocorrência de bauxita sobre rochas ígneas na Amazônia. Este trabalho detalha essa ocorrência, bem como a sobre a Formação Prosperança com base nos aspectos estruturais, texturais, mineralógicos e químicos (Fig. 1).

\section{GEOLOGIA, GEOMORFOLOGIA E FISIOGRA-}

FIA A região do Pitinga é constituída predominantemente por rochas efusivas ácidas do Grupo Iricoumé (perfil 1) e plútons graníticos (Água Boa - perfil 2) da Suíte Mapuera. São riolitos, riodacitos, quartzo-traquitos e piroclásticas com idade $1888 \pm 3 \mathrm{Ma}$ intrudido principalmente por biotita granitos, granitos rapakivi, albita granitos com idades entre $1794 \pm 19$ e $1815 \pm 5$ Ma (Costi et al. 2000 e Lenharo 2003).

A Formação Prosperança (perfil 3), a sul da área, representa a primeira sedimentação da bacia do Amazonas (Cunha et al. 1994). É constituída de arenitos arcoseanos, siltitos e conglomerados. Resultados de datação em zircão detrítico indicaram que a sedimentação teve início há pelo menos 1027 × 22 Ma (CPRM 2001).

Esses dois grupos de rochas se encaixam em duas unidades morfoestruturais: o Planalto Dissecado Norte

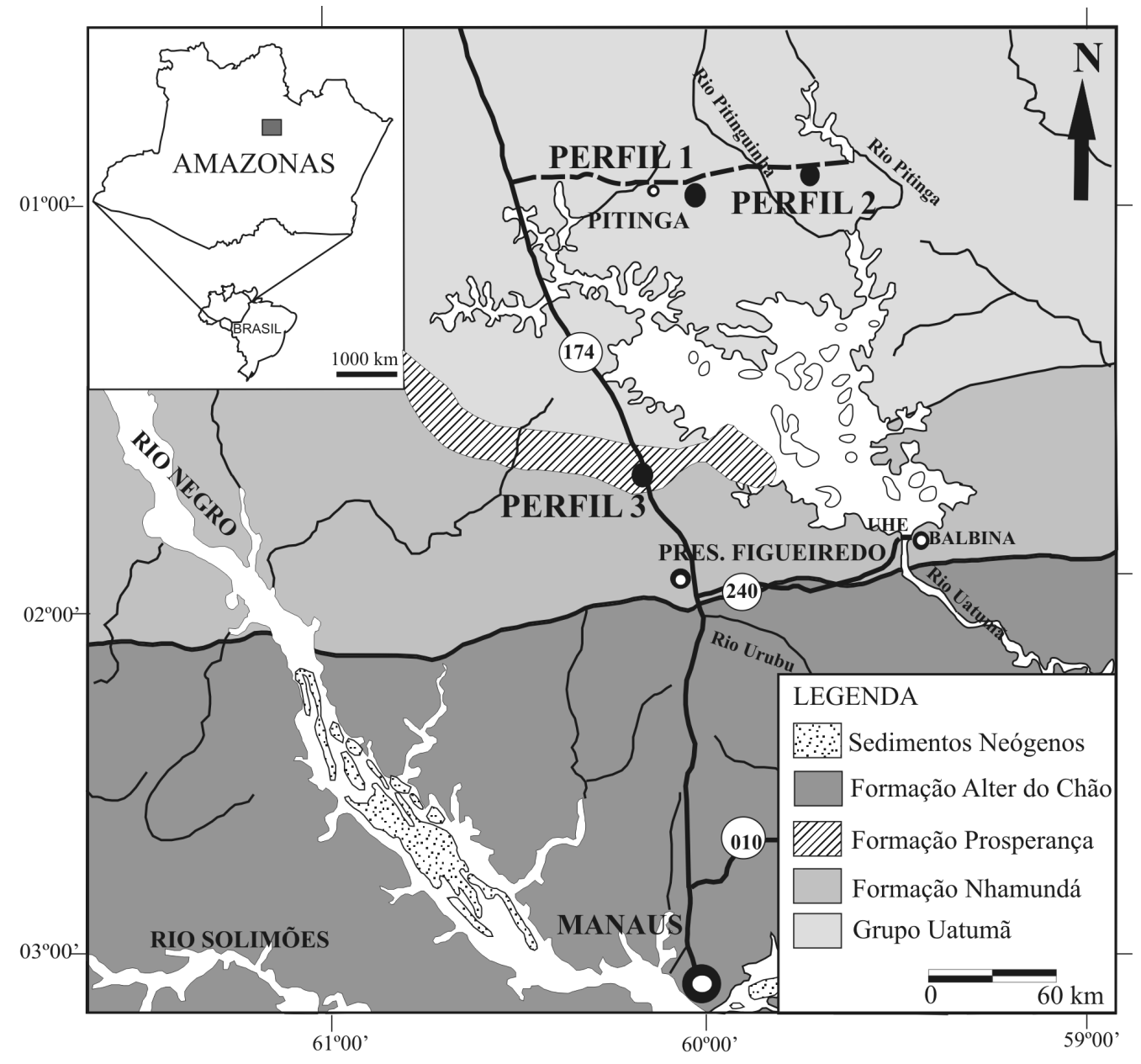

Figura 1 - Mapa geológico e de localização dos perfis estudados no NE do Amazonas. 
da Amazônia a norte e o Planalto da Bacia Sedimentar do Amazonas a sul. A primeira desenvolvida sobre as vulcânicas e granitos da região, consiste de extensos platôs com até $25 \mathrm{~km}$ de extensão com altitudes entre 100 e 450 $\mathrm{m}$, vales amplos e pouco aprofundados. O segundo sobre as rochas sedimentares paleozóicas da região, também é caracterizada por extensos platôs (até $22 \mathrm{~km}$ ), mas com altitudes menores, em média $100 \mathrm{~m}$, embora localmente possam atingir até $250 \mathrm{~m}$. Os vales são largos e pouco profundos encaixados em falhas com direções predominantes NE-SW e NW-SE (RADAMBRASIL 1978).

A vegetação da região é do tipo floresta densa, típica de clima tropical quente e úmido, com uma estação chuvosa de dezembro a maio, índice pluviométrico de $2000 \mathrm{~mm} /$ ano e temperatura média anual de $26{ }^{\circ} \mathrm{C}$.

MATERIAIS E MÉTODOS Para este estudo foram selecionados três perfis que representam o intemperismo sobre as rochas vulcânicas e plutônicas do Grupo Uatumã e sedimentares da Formação Prosperança num total de 27 amostras. Os perfis foram caracterizados em função dos aspectos físicos como textura, estrutura e cor, além da mineralogia e química. A mineralogia foi obtida por difração de raios- $\mathrm{x}$ e complementada com análise petrográfica, ambas no laboratório do Departamento de Geociências da Universidade Federal do Amazonas (UFAM). Os elementos maiores, na forma de seus óxi$\operatorname{dos}\left(\mathrm{SiO}_{2}, \mathrm{Al}_{2} \mathrm{O}_{3}, \mathrm{Fe}_{2} \mathrm{O}_{3}, \mathrm{TiO}_{2}, \mathrm{MgO}, \mathrm{CaO}, \mathrm{Na}_{2} \mathrm{O}\right.$ e $\left.\mathrm{K}_{2} \mathrm{O}\right)$, e a perda ao fogo $(\mathrm{PF})$ foram analisados por ICP-ES após fusão com $\mathrm{LiBO}_{2}$. Os elementos-traço por ICP-MS, alguns após abertura das amostras por fusão com $\mathrm{LiBO}_{2}$ (Mo, $\mathrm{Cu}, \mathrm{Pb}, \mathrm{Zn}, \mathrm{Ni}, \mathrm{As}, \mathrm{Cd}, \mathrm{Sb}, \mathrm{Bi}, \mathrm{Ag}, \mathrm{Au}, \mathrm{Hg}, \mathrm{Tl}$, $\mathrm{Se}, \mathrm{Ba}, \mathrm{Be}, \mathrm{Co}, \mathrm{Cs}, \mathrm{Ga}, \mathrm{Hf}, \mathrm{Nb}, \mathrm{Rb}, \mathrm{Sn}, \mathrm{Sr}, \mathrm{Ta}, \mathrm{Th}, \mathrm{U}$, $\mathrm{V}, \mathrm{W}, \mathrm{Zr}, \mathrm{Y}$ e ETR) enquanto outros por água-régia (Au, $\mathrm{Ag}, \mathrm{As}, \mathrm{Bi}, \mathrm{Cd}, \mathrm{Cu}, \mathrm{Hg}, \mathrm{Mo}, \mathrm{Ni}, \mathrm{Pb}, \mathrm{Sb}, \mathrm{Se}, \mathrm{Tl}$ e Zn). O Mn foi analisado por absorção atômica na UFAM após abertura ácida e todos os demais elementos pela Acme Analytical Laboratories LTD em Vancouver, Canadá.

O percentual correspondente a cada mineral ao longo dos perfis foi obtido por cálculo estequiométrico a partir dos dados de difratometria de raios-X e das análises químicas dos óxidos maiores (Tab. 1). O procedimento para esse cálculo está descrito na tabela 2 e constou das seguintes etapas: 1) nas amostras onde o quartzo é ausente o $\mathrm{SiO}_{2}$ foi atribuído à caulinita; 2) a diferença entre o percentual de $\mathrm{Al}_{2} \mathrm{O}_{3}$ em uma determinada amostra e o necessário para formar a caulinita corresponde, ao teor de gibbsita na amostra; 3 ) quando há caulinita e quartzo, todo o $\mathrm{Al}_{2} \mathrm{O}_{3}$ foi atribuído à caulinita. Este procedimento possibilitou estimar quanto de $\mathrm{SiO}_{2}$ do total foi necessário para formá-la. $\mathrm{O} \mathrm{SiO}_{2}$ restante foi atribuído ao teor de quartzo na amostra; 4) para as amostras com muscovita, illita e caulinita o cálculo teve início com a atribuição de todo $\mathrm{MgO}$ à illita (única possível fonte desse elemento nos minerais encontrados). Isso permitiu estimar o percentual de $\mathrm{K}_{2} \mathrm{O}$ proveniente da illita, o restante foi atribuído à muscovita; 5) o percentual de hematita+goethita foi obtido pela diferença entre o $\mathrm{Fe}_{2} \mathrm{O}_{3}$ total e o contido na illita, enquanto todo o $\mathrm{TiO}_{2}$ foi atribuído ao anatásio.
Tabela 1 - Minerais identificados nas amostras e suas respectivas composições centesimais.

\begin{tabular}{|c|c|}
\hline Mineral & Composição centesimal (CC) \\
\hline Quartzo: $\mathrm{SiO}_{2}$ & $100 \% \mathrm{SiO}_{2}$ \\
\hline $\begin{array}{l}\text { Caulinita: } \\
\mathrm{Al}_{2} \mathrm{O}_{3}\left(\mathrm{SiO}_{2}\right)_{2} \cdot 2 \mathrm{H}_{2} \mathrm{O}\end{array}$ & $\begin{array}{l}\mathrm{Al}_{2} \mathrm{O}_{3}=39,5 \% \mathrm{SiO}_{2}=46,49 \% \\
\mathrm{H}_{2} \mathrm{O}=14,01 \%\end{array}$ \\
\hline Gibbsita: $\mathrm{Al}(\mathrm{OH})_{3}$ & $\mathrm{Al}_{2} \mathrm{O}_{3}=65,37 \% \mathrm{H}_{2} \mathrm{O}=34,63 \%$ \\
\hline $\begin{array}{l}\text { Illita: } \\
\mathrm{KAl}_{6} \mathrm{Fe}_{2} \mathrm{Mg}_{2} \mathrm{Si}_{4} \mathrm{O}_{12} \mathrm{H}_{2}\end{array}$ & $\begin{array}{l}\mathrm{K}_{2} \mathrm{O}=5,8 \% \mathrm{Al}_{2} \mathrm{O}_{3}=37,7 \% \mathrm{Fe}_{2} \mathrm{O}_{3} \\
=19,68 \% \mathrm{MgO}=4,97 \% \mathrm{SiO}_{2}= \\
29,62 \% \mathrm{H}_{2} \mathrm{O}=2,22 \%\end{array}$ \\
\hline $\begin{array}{l}\text { Muscovita: } \\
\mathrm{KAl}_{2}(\mathrm{OH})_{2} \mathrm{AlSi}_{3} \mathrm{O}_{10}\end{array}$ & $\begin{array}{l}\mathrm{K}_{2} \mathrm{O}=11,82 \% \mathrm{Al}_{2} \mathrm{O}_{3}=38,4 \% \\
\mathrm{SiO}_{2}=45,26 \% \mathrm{H}_{2} \mathrm{O}=4,52 \%\end{array}$ \\
\hline $\begin{array}{l}\text { Hematita/Goethita: } \\
\mathrm{Fe}_{2} \mathrm{O}_{3}\end{array}$ & $100 \% \mathrm{Fe}_{2} \mathrm{O}_{3}$ \\
\hline Anatásio: $\mathrm{TiO}_{2}$ & $100 \% \mathrm{TiO}_{2}$ \\
\hline
\end{tabular}

Tabela 2 - Procedimento para a quantificação dos minerais presentes nas amostras que compõem os perfis estudados. $C C$ - composição centesimal.

\begin{tabular}{|c|c|}
\hline Mineral & Cálculo composicional \\
\hline Muscovita (M) & $\begin{array}{l}\mathrm{K}_{2} \mathrm{O}(\mathrm{M})=\mathrm{K}_{2} \mathrm{O} \text { total }-\mathrm{K}_{2} \mathrm{O}(\mathrm{I}) ; \mathrm{M}=\mathrm{K}_{2} \mathrm{O}(\mathrm{M}) \\
\mathrm{x} 100 / \mathrm{K}_{2} \mathrm{O}(\mathrm{CC}) \mathrm{M} ; \mathrm{Al}_{2} \mathrm{O}_{3}(\mathrm{M})=\mathrm{Al}_{2} \mathrm{O}_{3}(\mathrm{CC}) \\
\mathrm{M} \times \mathrm{M} / 100 ; \mathrm{SiO}_{2}(\mathrm{M})=\mathrm{SiO}_{2}(\mathrm{CC}) \mathrm{M} \times \mathrm{M} / \\
100 ;\end{array}$ \\
\hline Illita (I) & $\begin{array}{l}\mathrm{I}=\mathrm{MgO} \text { total x } 100 / \mathrm{MgO}(\mathrm{CC}) \mathrm{I} ; \mathrm{K}_{2} \mathrm{O}(\mathrm{I})= \\
\mathrm{K}_{2} \mathrm{O}(\mathrm{CC}) \mathrm{I} \times \mathrm{I} / 100 ; \mathrm{Al}_{2} \mathrm{O}_{3}(\mathrm{I})=\mathrm{Al}_{2} \mathrm{O}_{3}(\mathrm{CC}) \\
\mathrm{I} \times \mathrm{I} / 100 ; \mathrm{SiO}_{2}(\mathrm{I})=\mathrm{SiO}_{2}(\mathrm{CC}) \mathrm{I} \times \mathrm{I} / 100 ; \\
\mathrm{SiO}_{2}(\mathrm{C})=\mathrm{SiO}_{2}(\mathrm{CC}) \mathrm{C} \times \mathrm{C} / 100 ; \mathrm{Fe}_{2} \mathrm{O}_{3}(\mathrm{I})= \\
\mathrm{Fe}_{2} \mathrm{O}_{3}(\mathrm{CC}) \mathrm{I} \times \mathrm{I} / 100\end{array}$ \\
\hline Caulinita $(\mathrm{C})$ & $\begin{array}{l}\mathrm{C}=\mathrm{SiO}_{2} \text { total } \times 100 / \mathrm{SiO}_{2}(\mathrm{CC}) ; \mathrm{Al}_{2} \mathrm{O}_{3}(\mathrm{C}) \\
=\mathrm{C} \times \mathrm{Al}_{2} \mathrm{O}_{3}(\mathrm{CC}) / 100 ; \mathrm{C}=\mathrm{Al}_{2} \mathrm{O}_{3} \text { total } \times \\
100 / \mathrm{Al}_{2} \mathrm{O}_{3}(\mathrm{CC}) \mathrm{C} ; \mathrm{SiO}_{2}(\mathrm{C})=\mathrm{SiO}_{2}(\mathrm{CC}) \\
\mathrm{C} \times \mathrm{C} / 100 ; \mathrm{C}=\left[\mathrm{Al}_{2} \mathrm{O}_{3} \text { total }-\mathrm{Al}_{2} \mathrm{O}_{3}(\mathrm{I})-\right. \\
\left.\mathrm{Al}_{2} \mathrm{O}_{3}(\mathrm{M})\right] \times 100 / \mathrm{Al}_{2} \mathrm{O}_{3}(\mathrm{CC}) \mathrm{C}\end{array}$ \\
\hline Gibbsita (G) & $\begin{array}{l}\mathrm{Al}_{2} \mathrm{O}_{3}(\mathrm{G})=\mathrm{Al}_{2} \mathrm{O}_{3} \text { total }-\mathrm{Al}_{2} \mathrm{O}_{3}(\mathrm{C}) ; \mathrm{G}= \\
\mathrm{Al}_{2} \mathrm{O}_{3}(\mathrm{G}) \times 100 / \mathrm{Al}_{2} \mathrm{O}_{3}(\mathrm{CC}) \mathrm{G}\end{array}$ \\
\hline Quartzo (Q) & $\begin{array}{l}\mathrm{Q}=\mathrm{SiO}_{2} \text { total }-\mathrm{SiO}_{2}(\mathrm{C}) ; \mathrm{Q}=\mathrm{SiO}_{2} \text { total }- \\
\mathrm{SiO}_{2}(\mathrm{I})-\mathrm{SiO}_{2}(\mathrm{M})-\mathrm{SiO}_{2}(\mathrm{C})\end{array}$ \\
\hline $\begin{array}{l}\text { Hematita }+ \\
\text { Goethita }(\mathrm{H}+\mathrm{Gt})\end{array}$ & $\mathrm{H}+\mathrm{Gt}=\mathrm{Fe}_{2} \mathrm{O}_{3}$ total $-\mathrm{Fe}_{2} \mathrm{O}_{3}(\mathrm{I})$ \\
\hline Anatásio (An) & $\mathrm{An}=\mathrm{TiO}_{2}$ total \\
\hline
\end{tabular}

Os dados químicos foram tratados com o aplicativo STATISTICA 6.0 por análise de componentes principais (ACP). Essa técnica consiste em concentrar 
a variância dos dados em um número reduzido de componentes. Em conseqüência, a primeira componente principal (CP1) descreve a informação máxima dos dados originais; a segunda (CP2) a quantidade máxima da variação residual e assim por diante. A variância total quando plotada em um gráfico de $\mathrm{CP} 1$ versus $\mathrm{CP} 2$ pode revelar um padrão e este ser correlacionado às características estruturais, texturais, mineralógicas e químicas das amostras. Nesse trabalho essa técnica foi usada para definir os principais agrupamentos de elementos e amostras. $\mathrm{Fe}_{2} \mathrm{O}_{3}, \mathrm{Al}_{2} \mathrm{O}_{3}, \mathrm{SiO}_{2}, \mathrm{~K}_{2} \mathrm{O}, \mathrm{TiO}_{2} \mathrm{Zr}, \mathrm{Ba}, \mathrm{Nb}, \mathrm{Ga}$, $\mathrm{Y}, \mathrm{Hf}, \mathrm{Sr}, \mathrm{Th}, \mathrm{V}, \mathrm{Sn}, \mathrm{Pb}$, Ta, As e ETR são os que forneceram os agrupamentos mais importantes. Elementos abaixo do limite de detecção em muitas amostras (Co,
$\mathrm{Hg}, \mathrm{Sb}, \mathrm{Au}$ ) ou muito homogêneos entre os perfis (Mn, Sc, Mo, W, U, Zn) não foram tratados.

\section{PERFIL 1 - PERFIL SOBRE VULCÂNICAS DA FORMAÇÃO IRICOUMÉ}

Estruturação do perfil e mineralogia Saprólito, crosta laterítica, horizonte ou material desmantelado e solo formam os horizontes deste perfil (Fig. 2). O saprólito é areno-argiloso avermelhado a cinzento, possui porções argilosas esbranquiçadas e preserva a foliação incipiente da rocha-mãe. Gibbsita e caulinita dominam com 87\%, mas também ocorrem hematita, goethita, quartzo e anatásio (Tab. 3). A crosta laterítica está disposta imediatamente acima do saprólito, mede cerca
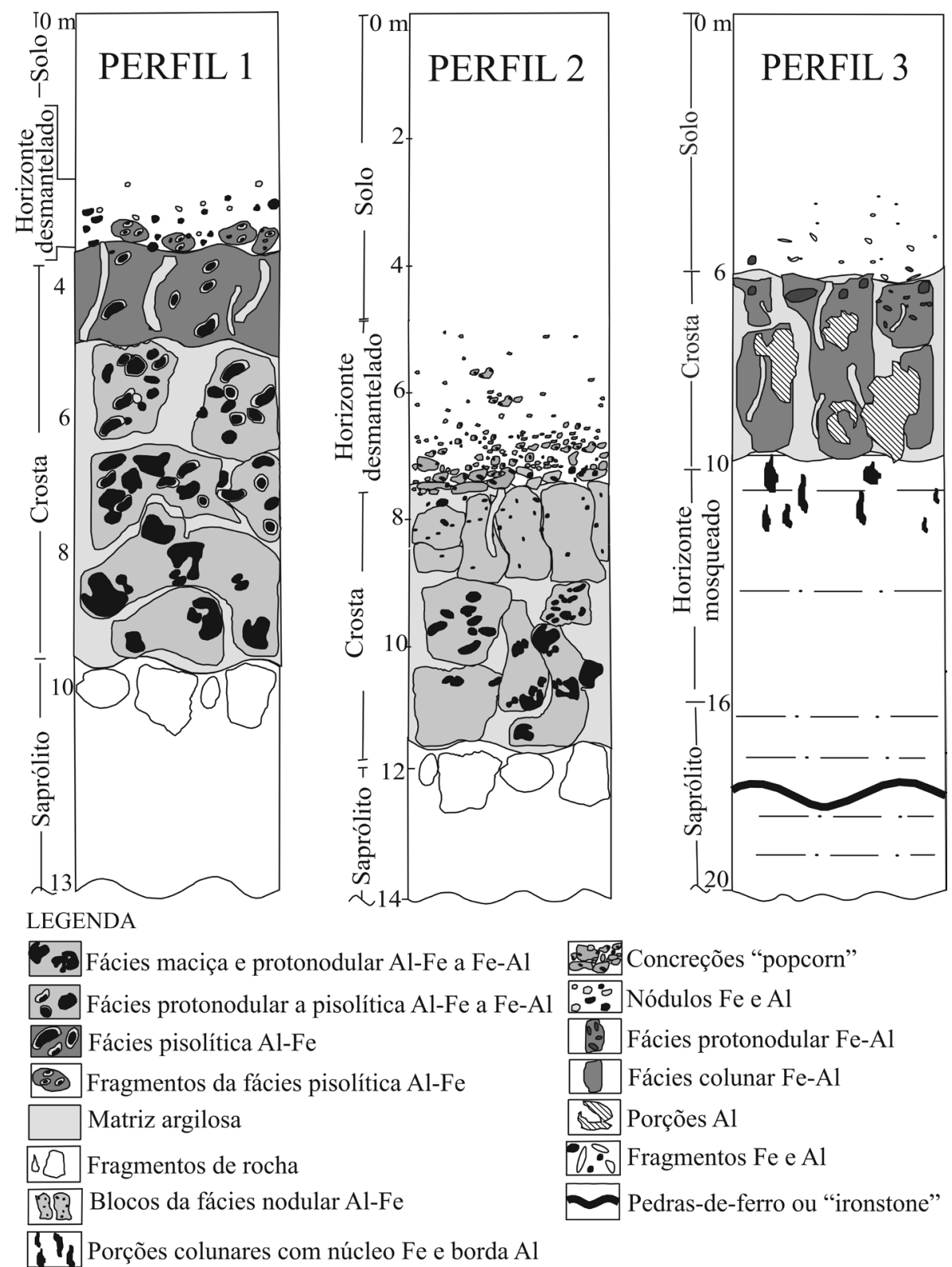

T. Porções colunares com núcleo Fe e borda Al

Figura 2 - Estruturação dos perfis lateríticos sobre rochas vulcânicas (Perfil 1) graniticas (Perfil 2) e sedimentares (Perfil 3) no NE do Amazonas. $F_{C}-$ fácies; $\mathrm{Al}$-aluminoso; $\mathrm{Fe}$-ferruginoso; $\mathrm{Fe}$ - $\mathrm{Al}$-ferro-aluminoso; $\mathrm{Al}-\mathrm{Fe}$ alumino-ferruginoso. 
$6 \mathrm{~m}$ de espessura e é composta de três fácies da base para o topo: maciça com porções protonodulares, protonodular a pisolítica e pisolítica (Fig. 3). Essas fácies variam entre aluminosa e ferro-aluminosa, são marrons avermelhadas e esbranquiçadas, cortadas por porções argilosas amareladas constituídas de caulinita e goethita. A gibbsita atinge $86 \%$ e predomina na fácies maciça e no plasma rosado e esbranquiçado que envolve os pisólitos hematíticos da crosta protonodular a pisolítica e pisolítica. A hematita ocorre associada à goethita (< $50 \%$ ) e dá coloração avermelhada às porções maciças, nodulares e pisolíticas. A caulinita é mais abundante no saprólito e no solo $(<35 \%)$, mas também compõe as porções argilosas da crosta onde o quartzo está em proporções reduzidas $(<1 \%)$; ambos também ocorrem junto a hematita nos pisólitos. Anatásio aumenta de teor em direção ao solo, mas não ultrapassa 4\% (Tab. 3).

O horizonte desmantelado que recobre a crosta tem 1,5 m de espessura (Fig. 2). É formado por fragmentos decimétricos e centimétricos da fácies pisolítica, envolvidos por matriz argilosa amarela-avermelhada, esta é constituída de gibbsita $(66 \%)$, caulinita $(15 \%)$,

Tabela 3 - Composição mineralógica, em \%, de amostras representativas dos perfis estudados. Fc-fácies; Hz-horizonte; HzM - horizonte mosqueado; F-fragmentos; $M$ - matriz; H-hematita; Gt-goethita.

\begin{tabular}{|c|c|c|c|c|c|c|c|c|}
\hline Horizontes & Quartzo & Caulinita & Gibbsita & $\mathrm{H}+\mathrm{Gt}$ & Anatásio & Muscovita & Illita & Total \\
\hline \multicolumn{9}{|c|}{ Perfil 1} \\
\hline Solo & $<1$ & 11 & 68 & 14 & 4 & & & 98 \\
\hline Hz. desmantelado (F) & $<1$ & 31 & 65 & 1 & 1 & & & 99 \\
\hline Hz. desmantelado (M) & $<1$ & 15 & 66 & 13 & 4 & & & 99 \\
\hline \multicolumn{9}{|l|}{ Crosta } \\
\hline F pisolítica & $<1$ & 8 & 87 & 3 & 1 & & & 100 \\
\hline $\begin{array}{l}\text { F protonodular } \\
\text { a pisolítica }\end{array}$ & $<1$ & 10 & 39 & 48 & 1 & & & 99 \\
\hline $\begin{array}{l}\text { F protonodular/ } \\
\text { pisolítica }\end{array}$ & $<1$ & 3 & 69 & 25 & 1 & & & 99 \\
\hline Fc. maciça & $<1$ & 3 & 86 & 9 & 1 & & & 100 \\
\hline Saprólito & $<1$ & 34 & 53 & 11 & 2 & & & 101 \\
\hline \multicolumn{9}{|c|}{ Perfil 2} \\
\hline Solo & $<1$ & 77 & 9 & 8 & 2 & & & 97 \\
\hline Hz. desmantelado (F) & $<1$ & 17 & 75 & 6 & 2 & & & 101 \\
\hline Hz desmantelado (M) & $<1$ & 79 & 9 & 7 & 2 & & & 98 \\
\hline \multicolumn{9}{|l|}{ Crosta } \\
\hline F protonodular & $<1$ & 13 & 38 & 47 & 2 & & & 101 \\
\hline F maciça & $<1$ & 18 & 66 & 14 & $<1$ & & & 99 \\
\hline Saprólito & 2 & 52 & 39 & 7 & $<1$ & & & 101 \\
\hline \multicolumn{9}{|c|}{ Perfil 3} \\
\hline Solo & $<1$ & 89 & 2 & 3 & 2 & & & 97 \\
\hline \multicolumn{9}{|l|}{ Crosta } \\
\hline F protonodular & 15 & 4 & 26 & 52 & $<1$ & & & 98 \\
\hline Matriz (topo) & 3 & 88 & 2 & 7 & 2 & & & 102 \\
\hline F colunar & 10 & 4 & 33 & 51 & $<1$ & & & 99 \\
\hline Matriz (base) & 2 & 77 & 8 & 13 & 1 & & & 101 \\
\hline Topo do HzM (F) & $<1$ & 14 & 80 & 4 & 1 & $<1$ & $<1$ & 100 \\
\hline Topo do HzM (M) & $<1$ & 76 & 17 & 2 & 2 & $<1$ & $<1$ & 98 \\
\hline Hz. mosqueado & 1 & 82 & 10 & 4 & 2 & $<1$ & $<1$ & 99 \\
\hline Hz. mosqueado & 6 & 90 & $<1$ & 2 & 1 & $<1$ & $<1$ & 100 \\
\hline Saprólito (F argilosa) & 5 & 71 & $<1$ & 10 & 2 & 7 & 3 & 99 \\
\hline Saprólito (F arenosa) & 94 & 4 & $<1$ & 1 & $<1$ & $<1$ & $<1$ & 100 \\
\hline
\end{tabular}




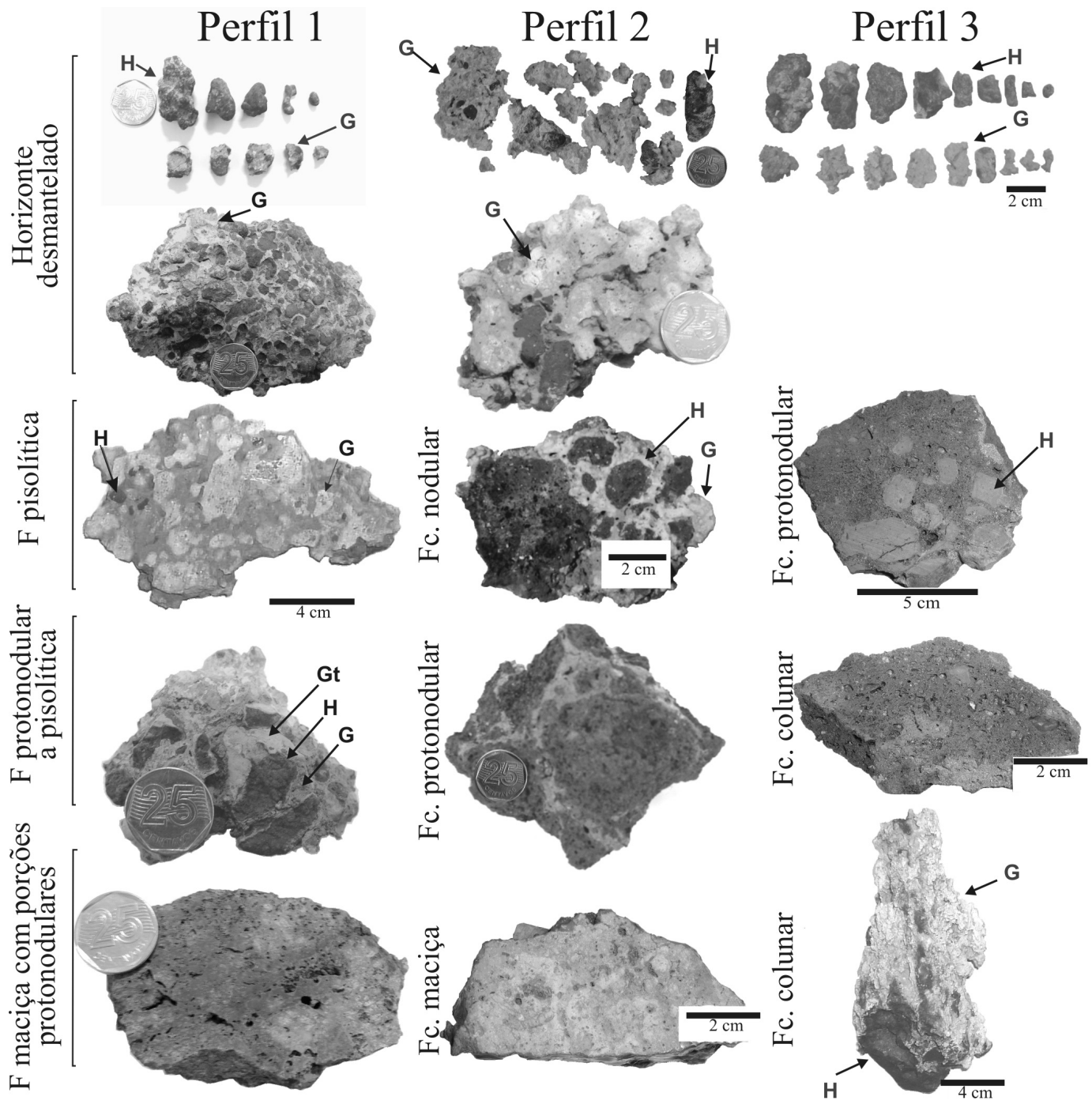

Figura 3 - Diferentes fácies da crosta laterítica e fragmentos dos perfis 1, 2 e 3. Fc-fácies; H-hematita; $G$ - gibbsita; Gt - goethita.

hematita e goethita (13\%) (Tab. 3). Os fragmentos maiores exibem feições côncavas revestidas por filme de goethita, moldes de porções anteriormente ocupadas por pisólitos hematíticos (Fig. 3). Os fragmentos menores são constituídos, principalmente de nódulos, tanto hematíticos, avermelhados e sub-arredondados, como gibbsíticos, amarelo-esbranquiçados, angulosos; ambos com até $3 \mathrm{~cm}$ de diâmetro e constituídos, em média, por $65 \%$ de gibbsita e $31 \%$ de caulinita. Recobrindo esse horizonte ocorre o solo, tem 2,5 m de espessura, é argilo-arenoso e passa de amarelado na base a cinza no topo. Possui composição mineralógica equivalente à da matriz do horizonte desmantelado sotoposto.

Composição química Os principais óxidos do perfil são $\mathrm{Al}_{2} \mathrm{O}_{3}$ e $\mathrm{SiO}_{2}$ (Tab. 4), relacionados a gibbsita e caulinita. $\mathrm{O} \mathrm{Al}_{2} \mathrm{O}_{3}$, constituinte fundamental da gibbsita, predomina nas fácies maciça da base $(58 \%)$ e pisolítica do topo da crosta $(60 \%)$, e também nos fragmentos do horizonte desmantelado (55\%). O teor mais baixo está na fácies protonodular a pisolítica $(29 \%)$ da porção intermediária da crosta (Fig. 4). A P.F. varia em torno de $30 \%$ no perfil e tem o mesmo comportamento do $\mathrm{Al}_{2} \mathrm{O}_{3}$. Por outro lado, $\mathrm{Fe}_{2} \mathrm{O}_{3}$ tem distribuição oposta, ou seja, aumenta de teor do saprólito $(\sim 10 \%)$ para a fácies protonodular na porção central da crosta (48\%), e diminui para menos de $2 \%$ nos fragmentos do horizonte desmantelado no topo do perfil. $\mathrm{O} \mathrm{SiO}_{2}$ não atinge $7 \%$, exceto no saprólito e nos fragmentos do horizonte desmantelado (15\%). Os teores de $\mathrm{TiO}_{2}$ aumentam progressivamente de $1 \%$ na base para $4 \%$ no topo do perfil, enquanto $\mathrm{CaO}, \mathrm{Na}_{2} \mathrm{O}, \mathrm{MgO}$ e $\mathrm{K}_{2} \mathrm{O}$ diminuem muito de teor da rocha mãe para o perfil onde raramente atingem $0,5 \%$. O $\mathrm{P}_{2} \mathrm{O}_{5}$ também está presente em teor muito baixo em todo o perfil e não ultrapassa $0,3 \%$ no saprólito.

Elementos-traço Os teores de $\mathrm{Zr}$, Th, $\mathrm{Nb}, \mathrm{Ga}, \mathrm{Hf}, \mathrm{Y}$, V, Sn, Sc, W, Ta, U e Hg no perfil são maiores do que a média crustal, Ba, Sr, Mn, Zn, Co, Ni, Rb e Au menores, enquanto $\mathrm{Pb}, \mathrm{V}, \mathrm{As}, \mathrm{Mo}, \mathrm{Cu}$ e $\mathrm{Sb}$ estão na mesma ordem de grandeza dela (Tab. 5). Os elementos mais abundantes no perfil, em ordem decrescente, são $\mathrm{Zr}, \mathrm{Ba}, \mathrm{Nb}, \mathrm{Ga}$, Th, 
Tabela 4 - Composição química, em \%, das amostras representativas dos perfis 1, 2 e 3. Fc-fácies; $\mathrm{Hz}$-horizonte; HzM - horizonte mosqueado; $F$-fragmentos; $M$-matriz.

\begin{tabular}{|c|c|c|c|c|c|c|c|}
\hline Horizontes & $\mathrm{SiO}_{2}$ & $\mathrm{Al}_{2} \mathrm{O}_{3}$ & $\mathrm{Fe}_{2} \mathrm{O}_{3}$ & $\mathrm{TiO}_{2}$ & $\mathrm{P}_{2} \mathrm{O}_{5}$ & P.F. & Total \\
\hline \multicolumn{8}{|c|}{ Perfil 1} \\
\hline Solo & 5,24 & 48,93 & 13,60 & 3,62 & 0,1 & 27,70 & 99,13 \\
\hline Hz. desmantelado (F) & 14,60 & 55,12 & 1,14 & 1,02 & $<0,01$ & 27,90 & 99,82 \\
\hline Hz. desmantelado (M) & 6,98 & 49,11 & 13,38 & 3,54 & 0,1 & 26,10 & 99,15 \\
\hline \multicolumn{8}{|l|}{ Crosta } \\
\hline F pisolítica & 3,82 & 59,88 & 3,37 & 1,32 & 0,03 & 31,30 & 99,73 \\
\hline $\begin{array}{l}\text { F protonodular/ } \\
\text { pisolítica }\end{array}$ & 4,54 & 29,27 & 47,55 & 0,94 & 0,06 & 17,40 & 99,74 \\
\hline $\begin{array}{c}\text { F protonodular a } \\
\text { pisolítica }\end{array}$ & 1,54 & 46,43 & 25,04 & 1,03 & 0,08 & 25,60 & 99,68 \\
\hline F maciça & 1,48 & 57,76 & 8,80 & 1,24 & 0,22 & 30,00 & 99,32 \\
\hline Saprólito & 15,79 & 47,79 & 10,54 & 1,46 & 0,29 & 23,40 & 99,09 \\
\hline Rocha-mãe $^{1}$ & 71,27 & 14,73 & 3,31 & 0,36 & 0,29 & 0,5 & 95,70 \\
\hline \multicolumn{8}{|c|}{ Perfil 2} \\
\hline Solo & 35,91 & 36,41 & 7,75 & 1,78 & 0,02 & 17,50 & 99,39 \\
\hline Hz. desmantelado (F) & 7,84 & 55,65 & 6,24 & 0,64 & $<0,01$ & 29,40 & 99,81 \\
\hline Hz. desmantelado (M) & 36,82 & 37,20 & 6,79 & 1,59 & $<0,01$ & 17,00 & 99,44 \\
\hline \multicolumn{8}{|l|}{ Crosta } \\
\hline F protonodular & 5,85 & 29,57 & 46,96 & 0,32 & 0,04 & 17,20 & 99,94 \\
\hline F maciça & 8,42 & 50,39 & 13,74 & 0,27 & $<0,01$ & 27,00 & 99,86 \\
\hline Saprólito & 24,28 & 45,92 & 6,70 & 0,42 & $<0,01$ & 22,40 & 99,76 \\
\hline Rocha-mãe $^{3}$ & 75,86 & 12,55 & 1,61 & 0,16 & 0,04 & 0,70 & 96,04 \\
\hline \multicolumn{8}{|c|}{ Perfil 3} \\
\hline Solo & 41,50 & 36,18 & 2,74 & 1,79 & 0,04 & 17,40 & 99,65 \\
\hline \multicolumn{8}{|l|}{ Crosta } \\
\hline F protonodular & 18,28 & 18,34 & 51,76 & 0,70 & 0,02 & 9,61 & 98,62 \\
\hline Matriz (topo) & 40,87 & 36,04 & 6,32 & 1,65 & 0,20 & 14,80 & 99,68 \\
\hline F colunar & 12,57 & 23,41 & 50,95 & 0,60 & 0,20 & 11,02 & 98,55 \\
\hline Matriz (base) & 35,70 & 35,59 & 13,27 & 1,02 & 0,10 & 14,71 & 100,29 \\
\hline Topo do HzM (F) & 6,58 & 57,88 & 3,56 & 1,18 & 0,02 & 30,50 & 99,74 \\
\hline Topo do HzM (M) & 35,22 & 40,84 & 2,02 & 1,82 & 0,04 & 19,70 & 99,64 \\
\hline Hz. mosqueado & 38,34 & 39,29 & 4,14 & 1,52 & 0,04 & 16,30 & 99,65 \\
\hline Hz. mosqueado & 47,79 & 35,51 & 1,66 & 1,04 & 0,05 & 13,60 & 99,69 \\
\hline Saprólito*(F argilosa) & 42,09 & 32,05 & 10,77 & 1,68 & 0,19 & 11,80 & 99,41 \\
\hline Saprólito (F arenosa) & 95,68 & 1,44 & 0,86 & 0,43 & 0,02 & 1,40 & 99,85 \\
\hline
\end{tabular}

* Única amostra com teores de $\mathrm{MgO}(0,17 \%)$ e $\mathrm{K}_{2} \mathrm{O}(1,02 \%)$ superiores ao limite de detecção $(0,01$ e $0,04 \%$, respectivamente).

$\mathrm{Na}_{2} \mathrm{O}$ e $\mathrm{CaO}$ são menores que $0,01 \%$.

${ }^{1}$ Vulcânica ácida (Costa et al. 1988): $\mathrm{Na}_{2} \mathrm{O}$ (2,53 \%), $\mathrm{CaO}(0,85$ \%) e $\mathrm{MgO}(0,28$ \%).

${ }^{2}$ Vulcânica ácida (CPRM 2000).

${ }^{3}$ Biotita granito (Lenharo et al. 2003): $\mathrm{Na}_{2} \mathrm{O}(3,71 \%), \mathrm{CaO}(0,05 \%)$ e $\mathrm{MgO}(0,04 \%)$. 

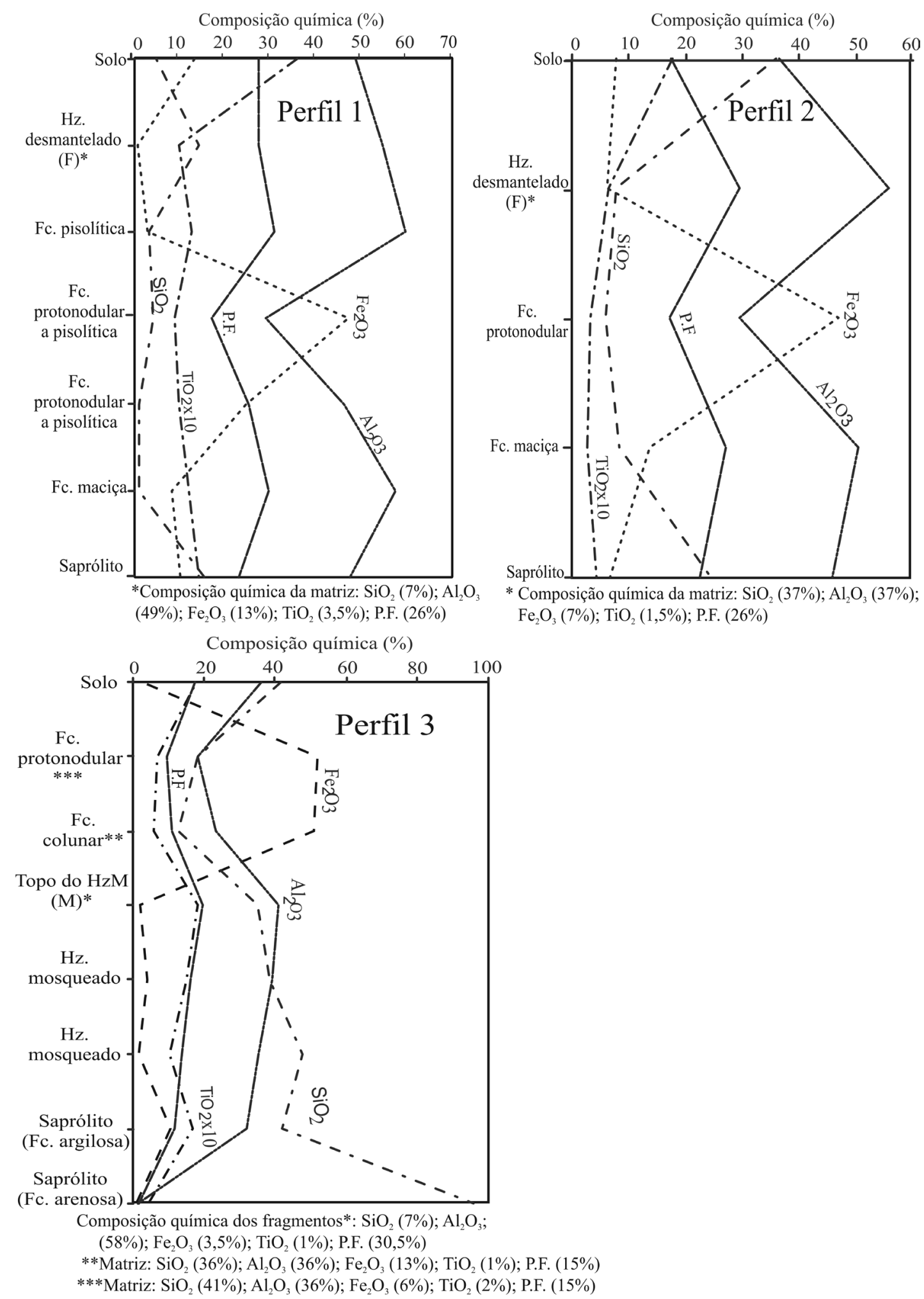

Figura 4 - Distribuição da composição química, em \%, das amostras representativas dos perfis 1, 2 e 3. Fc-fácies; HzM - horizonte mosqueado; F-fragmentos; $M$ - matriz.

Hf, Y, V, Sr e Mn, por outro lado, os menos são As, Ni, $\mathrm{Mo}, \mathrm{Cu}, \mathrm{Co}, \mathrm{Hg}, \mathrm{Sb}$ e Au. Desses, Zr, Th, Ga, Nb, Y e $\mathrm{Hf}$ predominam com teor similar na matriz argilosa do horizonte desmantelado e no solo, enquanto $\mathrm{V}, \mathrm{As}, \mathrm{Sb}$, $\mathrm{Cu}$ e Mo são mais abundantes na fácies protonodular a pisolítica da crosta devido associação com Fe (Fig. 5).

Os elementos terras raras (ETR) estão acima da média crustal, exceto Eu, Gd, Tb e Ho. Todos aumentam de teor para os horizontes do perfil em relação à rocha-mãe, exceto nos fragmentos do horizonte des- 
Tabela 5 - Composição química, em ppm, nas amostras representativas dos perfis 1, 2 e 3. Fc-fácies; Hz-horizonte; HzM - horizonte mosqueado; $F$ - fragmentos; $M$ - matriz.

\begin{tabular}{|c|c|c|c|c|c|c|c|c|c|c|c|c|c|c|c|c|c|c|c|c|c|c|c|c|c|c|}
\hline Amostra & $\mathrm{Zr}$ & $\mathrm{Ba}$ & $\mathrm{Nb}$ & $\mathrm{Ga}$ & $\mathrm{Y}$ & $\mathrm{Hf}$ & $\mathrm{Sr}$ & Th & $\mathrm{V}$ & Mn & $\mathrm{Sn}$ & $\mathrm{Sc}$ & $\mathrm{W}$ & $\mathrm{Pb}$ & $\mathrm{Ta}$ & $\mathrm{U}$ & $\mathrm{Zn}$ & $\mathrm{Rb}$ & As & $\mathrm{Ni}$ & Mo & $\mathrm{Cu}$ & Co & $\mathrm{Hg}$ & $\mathrm{Sb}$ & $\mathrm{Au}$ \\
\hline \multicolumn{27}{|c|}{ Perfil 1} \\
\hline Solo & 3757 & 156 & 147 & 108 & 100 & 104 & 76 & 152 & 143 & 22 & 50 & 23 & 12 & 5,2 & 10 & 15 & 12 & 1,1 & 1 & 1,8 & 0,9 & 6,2 & 0,6 & 0,13 & 0,6 & $<0,5$ \\
\hline $\begin{array}{l}\text { Hz desman- } \\
\text { telado }(\mathrm{F})\end{array}$ & 634 & 15 & $27 \mid$ & 73 & 9 & 18 & 12 & 24 & 42 & 15 & 4 & 4 & 2,5 & 1 & 1,9 & 2,2 & 1 & 2 & 1 & 0,6 & 0,3 & 0,2 & $<0,5$ & 0,18 & $<0,1$ & $<0,5$ \\
\hline $\begin{array}{l}\text { Hz desman- } \\
\text { telado (M) }\end{array}$ & 3596 & 159 & 146 & 108 & 101 & 100 & 83 & 156 & 141 & 25 & 26 & 24 & 12 & 4,1 & 10 & 15 & 3 & 2,1 & 1,2 & 0,6 & 0,7 & 0,6 & 0,6 & 0,09 & 0,6 & $<0,5$ \\
\hline \multicolumn{27}{|l|}{ Crosta } \\
\hline F pisolítica & 1122 & 55 & 54 & 64 & 38 & 32 & 29 & 55 & 35 & 17 & 11 & 11 & 4,8 & 2,2 & 3,9 & 6 & 1 & $<0,5$ & 1,5 & 0,3 & 0,4 & 0,5 & $<0,5$ & 0,31 & 0,6 & 1,3 \\
\hline $\begin{array}{l}\text { F proto- } \\
\text { nodular/ } \\
\text { pisolítica }\end{array}$ & 716 & 46 & 38 & 91 & 39 & 19 & 19 & 57 & 413 & 13 & 9 & 21 & 5,9 & 46 & 2,6 & 7,8 & 11 & 1 & 19 & 0,6 & 5,4 & 7,3 & 0,6 & 0,27 & 12 & 3,3 \\
\hline $\begin{array}{l}\text { F proto- } \\
\text { nodular/ } \\
\text { pisolítica }\end{array}$ & 865 & 140 & 44 & 68 & 40 & 26 & 45 & 53 & 161 & 14 & 8 & 10 & 4,3 & 11 & 2,8 & 5,2 & 5 & 1,8 & 12 & 0,3 & 2,8 & 4,5 & $<0,5$ & 0,15 & 9,2 & 3,4 \\
\hline F maciça & 1001 & 1232 & 61 & 69 & 66 & 28 & 165 & 66 & 34 & 45 & 8 & 11 & 4,8 & 13 & 4,1 & 7,2 & 13 & 1,2 & 2,2 & 0,7 & 0,4 & 1,7 & 2,4 & 0,06 & 4,1 & 1,4 \\
\hline Saprólito & 1137 & 1402 & 65 & 65 & 83 & 32 & 208 & 81 & 38 & 74 & 10 & 13 & 6 & 20 & 4,7 & 9,2 & 21 & 6,5 & 2 & 1 & 0,4 & 1,5 & 4,6 & 0,02 & 1,7 & 1,3 \\
\hline
\end{tabular}

Perfil 2

\begin{tabular}{l|c|c|c|c|c|c|c|c|c|c|c|c|c|c|c|c|c|c|c|c|c|c|c|c|c|c|c}
\hline Solo & 2531 & 9,4 & 441 & 187 & 95 & 119 & 16 & 325 & 80 & 21 & 248 & 7 & 36 & 0,9 & 41 & 19 & 4 & 1,3 & 2,9 & 1,3 & 1,8 & 0,4 & $<0,5$ & 0,14 & 0,1 & $<0,5$ \\
\hline $\begin{array}{l}\text { Hz desman- } \\
\text { telado (F) }\end{array}$ & 746 & 5,1 & 166 & 156 & 32 & 35 & 5,2 & 175 & 80 & 11 & 83 & 3 & 21 & 0,7 & 13 & 5,8 & 1 & $<0,5$ & 18 & 0,3 & 3,4 & 0,3 & $<0,5$ & 0,19 & 0,5 & 2,8 \\
\hline $\begin{array}{l}\text { Hz desman- } \\
\text { telado (M) }\end{array}$ & 2219 & 7,5 & 443 & 175 & 87 & 103 & 11 & 294 & 61 & 16 & 382 & 6 & 36 & 2,2 & 41 & 16 & 76 & 1,2 & 3,7 & 2,9 & 1,7 & 80 & $<0,5$ & 0,06 & 0,1 & 0,9 \\
\hline $\begin{array}{l}\text { Crosta } \\
\begin{array}{l}\text { Fproto- } \\
\text { nodular }\end{array}\end{array}$ & 512 & 1,2 & 151 & 136 & 21 & 26 & 1,9 & 319 & 304 & 14 & 57 & 4 & 19,8 & 45 & 12 & 5,8 & 3 & 0,6 & 44 & 0,1 & 18 & 2,4 & $<0,5$ & 0,67 & 7,4 & 8,5 \\
\hline F maciça & 445 & 2,1 & 181 & 110 & 29 & 25 & 3,3 & 127 & 30 & 10 & 54 & 3 & 15 & 7,5 & 17 & 4,8 & 2 & 1,1 & 10 & 0,1 & 2,8 & 1,8 & $<0,5$ & 0,24 & 1,9 & 6,8 \\
\hline \begin{tabular}{l} 
Saprólito \\
\hline
\end{tabular} & 823 & 1,1 & 267 & 111 & 53 & 43 & 1,7 & 101 & 12 & 8,1 & 90 & 3 & 18 & 5 & 24 & 8,3 & 2 & 0,7 & 6,1 & 0,3 & 1,3 & 0,6 & $<0,5$ & 0,06 & 1 & 2,6 \\
\hline
\end{tabular}

Perfil 3

\begin{tabular}{l|c|c|c|c|c|c|c|c|c|c|c|c|c|c|c|c|c|c|c|c|c|c|c|c|c|c|c}
\hline Solo & 1308 & 41 & 54 & 54 & 21 & 40 & 39 & 48 & 65 & 18 & 7 & 8 & 4,3 & 2,7 & 3,8 & 4,6 & 2 & 1,1 & 1 & 0,8 & 0,3 & 0,5 & $<0,5$ & 0,19 & $<0,1$ & 1,3 \\
\hline $\begin{array}{l}\text { Topo do } \\
\text { HzM (F) }\end{array}$ & 1076 & 37 & 51 & 71 & 35 & 31 & 21 & 50 & 29 & 8,9 & 20 & 10 & 4,8 & 1,3 & 3,6 & 5,5 & 2 & 0,9 & 2,7 & 0,5 & 0,3 & 0,4 & $<0,5$ & 0,25 & 0,3 & 0,6 \\
\hline $\begin{array}{l}\text { Topo do } \\
\text { HzM (M) }\end{array}$ & 1158 & 48 & 53 & 53 & 17 & 34 & 39 & 44 & 63 & 15 & 7 & 8 & 4,3 & 2,4 & 3,8 & 3,8 & 2 & 1,1 & 0,9 & 1,2 & 0,2 & 0,9 & $<0,5$ & 0,12 & 0,1 & 1,2 \\
\hline $\begin{array}{l}\text { Hz mos- } \\
\text { queado }\end{array}$ & 1192 & 83 & 47 & 52 & 18 & 34 & 58 & 42 & 80 & 13 & 5 & 8 & 4,2 & 4 & 3,3 & 3,5 & 0,1 & 2,8 & 1,4 & 0,7 & 0,4 & 0,5 & 0,6 & 0,1 & 0,1 & 0,7 \\
\hline $\begin{array}{l}\text { Hz mos- } \\
\text { queado }\end{array}$ & 744 & 89 & 33 & 39 & 26 & 22 & 59 & 32 & 67 & 15 & 4 & 7 & 2,3 & 3,1 & 2,3 & 3,1 & 1 & 5,7 & $<0,5$ & 0,3 & 0,2 & 0,1 & 0,6 & 0,02 & 0,1 & 1,1 \\
\hline $\begin{array}{l}\text { Saprólito } \\
\text { (F argilosa) }\end{array}$ & 432 & 752 & 28 & 37 & 37 & 13 & 207 & 23 & 236 & 13 & 6 & 11 & 3,1 & 8,6 & 2,2 & 8,1 & 4 & 38 & 8,3 & 3,2 & 0,5 & 7,7 & 2,8 & 0,01 & 0,5 & 1,7 \\
\hline $\begin{array}{l}\text { Saprólito } \\
\text { F arenosa) }\end{array}$ & 348 & 80 & 13 & 1,6 & 11 & 10 & 35 & 6,4 & 21 & 9,7 & $<1$ & 1 & 0,5 & 1,2 & 0,9 & 0,9 & 1 & 0,7 & $<0,5$ & 0,2 & 0,1 & 0,9 & $<0,5$ & $<0,01$ & 0,1 & 0,7 \\
\hline \begin{tabular}{l} 
IMédia crustal \\
\hline
\end{tabular} & 150 & 580 & 20 & 26 & 30 & 3 & 300 & 10 & 150 & 1000 & 2 & 13 & 1 & 10 & 0,45 & 2,5 & 80 & 150 & 2 & 75 & 1,5 & 50 & 25 & 0,02 & 0,1 & 3 \\
\hline
\end{tabular}

Elementos abaixo do limite de detecção: $\mathrm{Cd}(<0,1), \mathrm{Bi}(<0,1), \mathrm{Ag}(<0,1), \mathrm{Tl}(<0,1), \operatorname{Se}(<0,5)$, $\mathrm{Cs}(<0,5)$ e $\operatorname{Be}\left(<1\right.$ ppm). Rose et al. $(1979)^{1}$.

mantelado onde diminuíram três ou quatro vezes (Tab. 6). As razões $\mathrm{La}_{\mathrm{N}} / \mathrm{Lu}_{\mathrm{N}}$ (entre 5 e 16) revelam enriquecimento acentuado dos terras raras leves (ETRL) em relação aos pesados (ETRP), com valores mais altos na porção inferior do perfil (saprólito e fácies maciça) e mais baixos na superior (fácies pisolítica, desmantelado 

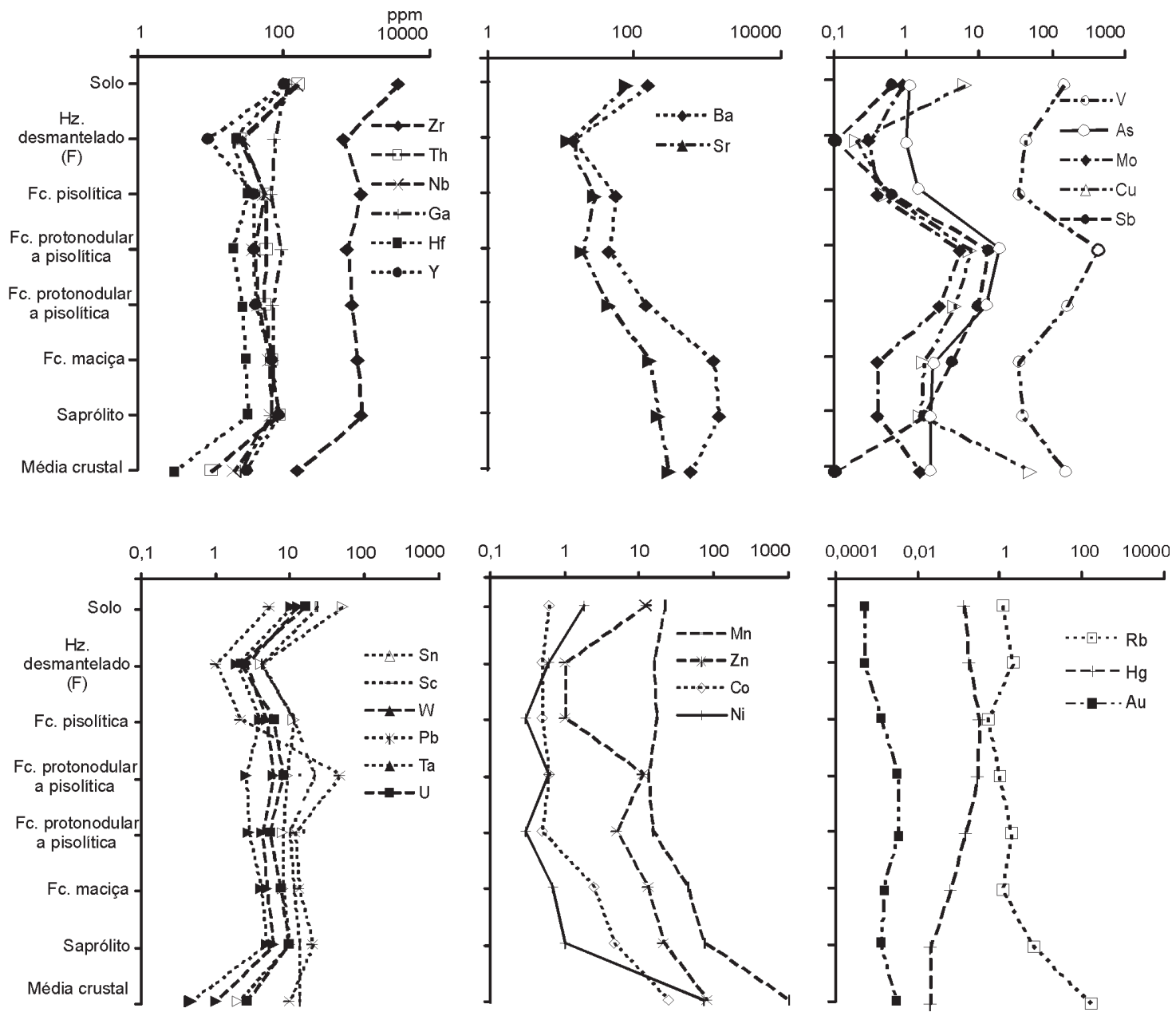

Figura 5 - Distribuição dos elementos-traço no perfil 1 . Hz - horizonte; Fc - fácies; Ffragmentos. Os valores dos elementos-traços da matriz do horizonte desmantelado estão na tabela 5 .

e solo). O paralelismo da curvas dos ETR em relação aos condritos demonstra a forte correlação química entre os horizontes (Fig. 6).

\section{PERFIL 2 - PERFIL SOBRE GRANITOS DA SUÍ- TE MAPUERA}

Estruturação do perfil e mineralogia A diferença de estrutura deste perfil em relação ao anterior está restrita à espessura de cada horizonte. A crosta do perfil 2 é menos espessa $(5 \mathrm{~m})$ que do perfil 1 , enquanto o horizonte desmantelado $(2 \mathrm{~m})$ e o solo $(5,5 \mathrm{~m})$ mais espessos. A crosta é formada pelas fácies maciça, protonodular e nodular e difere da crosta do perfil anterior pela ausência de córtex goethítico nos nódulos (Fig. 2 e 3). Quanto à mineralogia os dois perfis são muito semelhantes. Caulinita, gibbsita, hematita, goethita, quartzo e anatásio também são os minerais essenciais deste perfil, entretanto, ele difere do anterior por apresentar cerca de $80 \%$ de caulinita na matriz do horizonte desmantelado e no solo (Tab. 3). Neste perfil, bem como o sobre a rocha vulcânica (perfil 1), a fácies protonodular é a mais ferruginosa.
Composição química A composição química deste perfil é semelhante à do perfil 1 mas com teores levemente inferiores de $\mathrm{Al}_{2} \mathrm{O}_{3}$, P.F. e $\mathrm{TiO}_{2}$ (Fig. 4). Apesar de conter, em média, menos $\mathrm{Fe}_{2} \mathrm{O}_{3}$ que o perfil 1, sua crosta e fragmentos possuem maior teor nesse constituinte, principalmente onde a textura é protonodular. Este perfil possui, em média, três vezes mais $\mathrm{SiO}_{2}$ que o perfil 1 (Tab. 4), mas também é pobre em álcalis e $\mathrm{P}_{2} \mathrm{O}_{5}$, que ocorrem freqüentemente abaixo do limite de detecção.

Elementos-traço $\mathrm{Zr}$, Th, Nb, Ga, Hf, Sn, Y, W, Ta, e U são mais elevados que a média crustal, $\mathrm{V}, \mathrm{Mn}, \mathrm{Pb}, \mathrm{Sc}$, $\mathrm{Zn}, \mathrm{Cu}, \mathrm{Sr}, \mathrm{Ba}, \mathrm{Rb}$ e Ni menos, enquanto $\mathrm{As}, \mathrm{Mo}, \mathrm{Hg}$, $\mathrm{Sb}$ e $\mathrm{Au}$ ocorrem na mesma ordem de grandeza dela (Tab. 5). Os elementos-traço deste perfil predominam nos mesmos horizontes que no anterior (matriz do desmantelado e solo) e em concentrações similares, exceto Th em média o dobro do perfil 1 (101 - 325 ppm), Ba que está abaixo de $10 \mathrm{ppm}$ e $\mathrm{Cu}$ é mais de 130 vezes mais abundante na matriz do horizonte desmantelado deste perfil (80 ppm) que do anterior. Os teores de V, $\mathrm{Pb}, \mathrm{As}, \mathrm{Mo}$ e Sb são equivalentes ao do perfil 1 e têm a mesma distribuição, ou seja, são mais abundantes na 
Tabela 6 - Composição química, em ppm, dos elementos terras raras em amostras representativas dos perfis estudados. Fc-fácies; $\mathrm{Hz}$-horizonte; HzM - horizonte mosqueado; $\mathrm{F}$-fragmentos; $M$ - matriz.

\begin{tabular}{l|l|l|l|l|l|l|l|l|l|l|l|l|l|l|l|l|l|l|l|l|l}
\hline Amostra & $\mathrm{La}$ & $\mathrm{Ce}$ & $\operatorname{Pr}$ & $\mathrm{Nd}$ & $\mathrm{Sm}$ & $\mathrm{Eu}$ & $\mathrm{Gd}$ & $\mathrm{Tb}$ & $\mathrm{Dy}$ & $\mathrm{Ho}$ & $\mathrm{Er}$ & $\mathrm{Tm}$ & $\mathrm{Yb}$ & $\mathrm{Lu}$ & $\Sigma \mathrm{ETRL}$ & $\Sigma \mathrm{ETRP}$ & $\Sigma \mathrm{ETR}$ & $\mathrm{La}_{\mathrm{N}} /$ & $\begin{array}{c}\mathrm{La}_{\mathrm{N}} / \\
\mathrm{Lu}_{\mathrm{N}}\end{array}$ & $\mathrm{Gd}_{\mathrm{N}} /$ & $\mathrm{Eu} /$ \\
$\mathrm{Lu}_{\mathrm{N}}$ & $\mathrm{Eu}^{*}$ \\
\hline
\end{tabular}

Perfil 1

\begin{tabular}{l|c|c|c|c|c|c|c|c|c|c|c|c|c|c|c|c|c|c|c|c|c}
\hline Solo & 143 & 271 & 26 & 82 & 12 & 2,0 & 9,4 & 1,9 & 14 & 3,3 & 12 & 2,2 & 17 & 2,9 & 537 & 62 & 599 & 5,18 & 16,85 & 0,41 & 0,55 \\
\hline $\begin{array}{l}\text { Hz desmantela } \\
\text { do (F) }\end{array}$ & 19 & 27 & 2 & 8 & 1 & 0,2 & 0,9 & 0,2 & 1 & 0,3 & 1 & 0,2 & 2 & 0,3 & 57 & 5,7 & 63 & 7,11 & 19,08 & 0,40 & 0,74 \\
\hline $\begin{array}{l}\text { Hz desmantela } \\
\text { do (M) }\end{array}$ & 148 & 275 & 27 & 82 & 13 & 2,0 & 9,6 & 2,0 & 15 & 3,3 & 12 & 2,1 & 16 & 2,7 & 547 & 63 & 610 & 5,64 & 17,78 & 0,44 & 0,51 \\
\hline
\end{tabular}

Crosta

\begin{tabular}{|c|c|c|c|c|c|c|c|c|c|c|c|c|c|c|c|c|c|c|c|c|c|}
\hline F pisolítica & 59 & 105 & 10 & 31 & 5 & 0,8 & 3,7 & 0,8 & 6 & 1,2 & 4 & 0,8 & 6 & 1,0 & 210 & 24 & 234 & 6,02 & 18,29 & 0,46 & 0,53 \\
\hline $\begin{array}{l}\text { F protonodu } \\
\text { lar/pisolítica }\end{array}$ & 51 & 93 & 11 & 38 & 8 & 1,3 & 5,6 & 1,2 & 8 & 1,7 & 6 & 1,0 & 7 & 1,0 & 202 & 31 & 233 & 5,41 & 9,62 & 0,72 & 0,56 \\
\hline $\begin{array}{l}\text { F protonodu- } \\
\text { lar/pisolítica }\end{array}$ & 109 & 132 & 18 & 52 & 7 & 1,1 & 4,5 & 1,0 & 6 & 1,3 & 5 & 0,8 & 6 & 1,0 & 320 & 25 & 345 & 11,71 & 22,76 & 0,57 & 0,57 \\
\hline F maciça & 199 & 307 & 37 & 125 & 19 & 2,9 & 14 & 2,3 & 12 & 2,3 & 7 & 1,2 & 8 & 1,3 & 690 & 49 & 739 & 15,74 & 16,20 & 1,35 & 0,52 \\
\hline Saprólito & 251 & 483 & 50 & 168 & 25 & 3,7 & 16 & 3,0 & 16 & 3,0 & 9 & 1,5 & 11 & 1,7 & 980 & 61 & 1042 & 15,39 & 15,98 & 1,20 & 0,53 \\
\hline Dacito $^{1}$ & 34 & 78 & n.a & 31 & 4,8 & 1 & 2,7 & n.a & 1,9 & 0,4 & 0,8 & n.a & 0,6 & 0,1 & & & & & & & \\
\hline
\end{tabular}

Perfil 2

\begin{tabular}{l|c|c|c|c|c|c|c|c|c|c|c|c|c|c|c|c|c|c|c|c|c}
\hline Solo & 14 & 31 & 2,8 & 9,7 & 3,0 & 0,4 & 5,0 & 1,7 & 13 & 3,2 & 13 & 2,5 & 20 & 3,2 & 61 & 61 & 122 & 0,44 & 7,93 & 0,19 & 0,32 \\
\hline $\begin{array}{l}\text { Hz desmantela } \\
\text { do (F) }\end{array}$ & 7 & 14 & 1,2 & 4,7 & 1,0 & 0,1 & 1,5 & 0,5 & 4 & 1,1 & 4 & 0,8 & 6 & 1,1 & 28 & 19 & 47 & 0,69 & 11,86 & 0,17 & 0,36 \\
\hline $\begin{array}{l}\text { Hz desmantela } \\
\text { do (M) }\end{array}$ & 12 & 29 & 2,5 & 8,8 & 2,5 & 0,3 & 4,5 & 1,5 & 12 & 2,9 & 11 & 2,3 & 17 & 2,9 & 55 & 54 & 109 & 0,43 & 10,34 & 0,19 & 0,25 \\
\hline
\end{tabular}

Crosta

\begin{tabular}{l|c|c|c|c|c|c|c|c|c|c|c|c|c|c|c|c|c|c|c|c|c}
\hline $\begin{array}{c}\text { F protonodu } \\
\text { lar }\end{array}$ & 5 & 9 & 0,8 & 2,4 & 0,6 & 0,1 & 1,0 & 0,3 & 3 & 0,7 & 3 & 0,6 & 5 & 0,9 & 18 & 13 & 31 & 0,62 & 20,16 & 0,15 & 0,23 \\
\hline F maciça & 3 & 5 & 0,4 & 1,2 & 0,4 & 0,1 & 0,9 & 0,3 & 3 & 0,8 & 4 & 0,7 & 6 & 1,0 & 10 & 17 & 27 & 0,30 & 13,76 & 0,11 & 0,25 \\
\hline Saprólito $^{2}$ & 3 & 8 & 0,5 & 1,7 & 0,7 & 0,1 & 1,6 & 0,6 & 6 & 1,6 & 7 & 1,4 & 12 & 2,0 & 14 & 31 & 45 & 0,14 & 9,15 & 0,10 & 0,20 \\
\hline Biotita granito $^{2}$ & 37 & 97 & n.a & 33 & 7 & 0,26 & 4,8 & n.a & 6,6 & 1,5 & 4,7 & n.a & 6 & 0,78 & & & & & & & \\
\hline
\end{tabular}

Perfil 3

\begin{tabular}{l|l|l|l|l|l|l|l|l|l|l|l|l|l|l|l|l|l|l|l|l|l|l}
\hline Solo & 46 & 76 & 7 & 22 & 3,3 & 0,7 & 2,6 & 0,4 & 3,1 & 0,7 & 2,4 & 0,4 & 3,4 & 0,6 & 155 & 14 & 169 & 8,04 & 15,49 & 0,54 & 0,71 \\
\hline $\begin{array}{l}\text { Topo do HzM } \\
\text { (F) }\end{array}$ & 46 & 86 & 8 & 22 & 4,0 & 0,6 & 3,0 & 0,7 & 4,8 & 1,2 & 4,3 & 0,8 & 5,9 & 1,0 & 167 & 21,7 & 188 & 4,99 & 17,77 & 0,39 & 0,52 \\
\hline $\begin{array}{l}\text { Topo do HzM } \\
\text { (M) }\end{array}$ & 56 & 90 & 7 & 24 & 3,4 & 0,7 & 2,2 & 0,4 & 2,8 & 0,6 & 2,1 & 0,4 & 3,1 & 0,5 & 181 & 12 & 194 & 11,71 & 19,39 & 0,54 & 0,73 \\
\hline HzM & 78 & 132 & 11 & 37 & 5,4 & 1,1 & 3,4 & 0,5 & 3,1 & 0,6 & 2,2 & 0,4 & 3,1 & 0,6 & 265 & 14 & 278 & 14,63 & 17,34 & 0,76 & 0,71 \\
\hline HzM & 87 & 168 & 11 & 31 & 4,7 & 0,9 & 3,0 & 0,6 & 3,9 & 0,8 & 2,9 & 0,5 & 3,5 & 0,6 & 302 & 16 & 318 & 16,36 & 22,85 & 0,68 & 0,68 \\
\hline $\begin{array}{l}\text { Saprólito } \\
\text { F argilosa) }\end{array}$ & 120 & 312 & 40 & 170 & 30 & 5,9 & 18 & 2,5 & 10 & 1,5 & 4,0 & 0,7 & 4,6 & 0,7 & 677 & 42 & 719 & 18,10 & 4,88 & 3,18 & 0,73 \\
\hline $\begin{array}{l}\text { Saprólito } \\
\text { F arenosa) }\end{array}$ & 16 & 33 & 3 & 13 & 2,6 & 0,5 & 2,2 & 0,4 & 2,0 & 0,4 & 1,2 & 0,2 & 1,5 & 0,2 & 69 & 8,1 & 77 & 8,06 & 8,06 & 1,31 & 0,60 \\
\hline \begin{tabular}{l} 
Media crustal \\
\hline
\end{tabular} & 30 & 60 & 8,2 & 28 & 6 & 1,2 & 5,4 & 0,9 & 3 & 1,2 & 2,8 & 0,5 & 3 & 0,5 & & & & & & & \\
\hline
\end{tabular}

Dacito (CPRM, 2000)1 , biotita granito (Lenharo et al., 2000)², média da crosta continental (Taylor, 1964)³. n.a = elemento não analisado. 

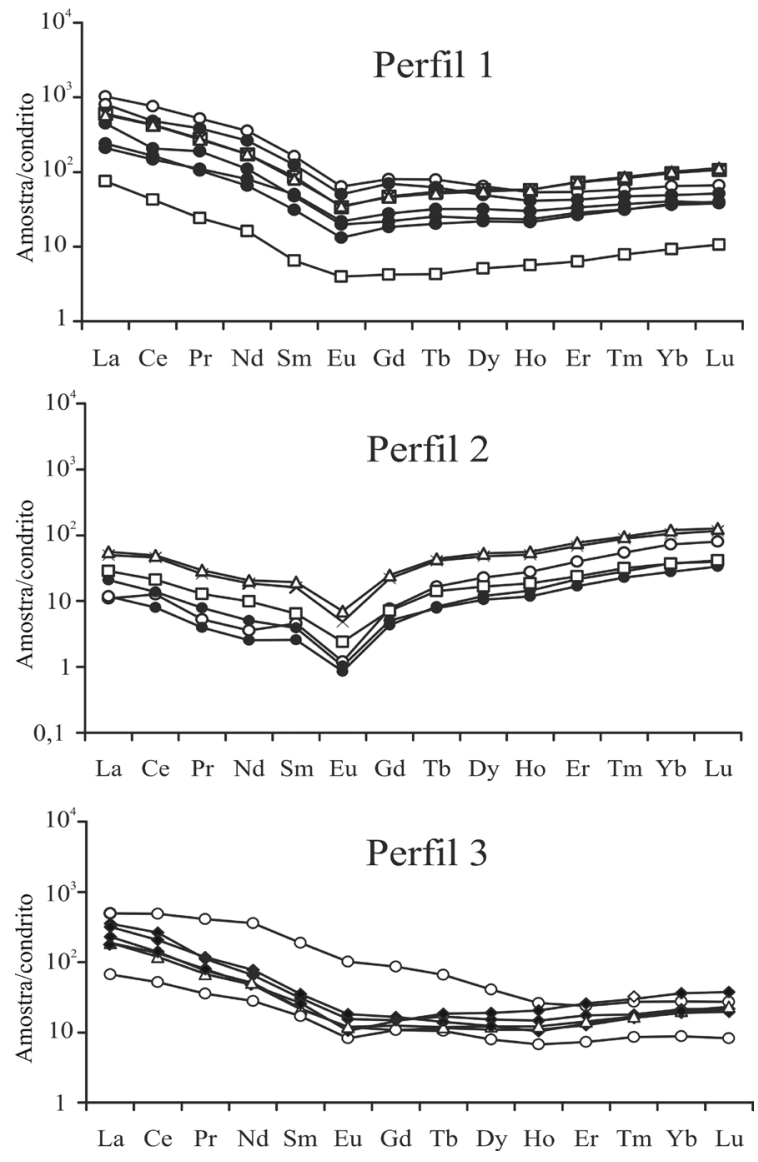

Figura 6 - Padrão de distribuição dos elementos terras raras nos perfis 1, 2 e 3. ○-saprólito; horizonte mosqueado; $\bullet$-crosta; $\square$-fragmentos do horizonte desmantelado; $\times$ - matriz do horizonte desmantelado; $\Delta$ - solo.

fácies protonodular (Fig. 7).

O conteúdo de ETR neste perfil é, em média, dez vezes menor que no anterior (Tab. 6). Er, Tm, $\mathrm{Yb}$ e Lu ocorrem acima da média crustal, La, Ce, Pr, Nd, Sm, $\mathrm{Eu}, \mathrm{Gd}$ e Tb abaixo, enquanto Dy e Ho estão presentes na mesma ordem de grandeza que ela (Fig. 6). Praticamente não há diferença entre o conteúdo de ETR leves $(49 \%)$ e pesados (51\%) no perfil; concentram-se no solo $(\Sigma \mathrm{ETR}=122 \mathrm{ppm})$ e na matriz argilosa do horizonte desmantelado $(\Sigma \mathrm{ETR}=109 \mathrm{ppm})$, onde se destacam Ce e Yb. Ao contrário do perfil 1, houve empobrecimento dos ETRL em relação aos ETRP, conforme indica a razão $\mathrm{La}_{\mathrm{N}} / \mathrm{Lu}_{\mathrm{N}}(0,14$ a 0,69$)$. Esta razão chega a ser mais de cem vezes menor que no perfil 1 e, ao contrário dele, aumenta da base para o topo.

\section{PERFIL 3 - PERFIL SOBRE A FORMAÇÃO PROSPERANÇA}

Estruturação do perfil e mineralogia Não há na região exposição de um perfil completo sobre essa unidade. Para o compor foram utilizadas duas exposições distantes $5 \mathrm{~km}$ e que correspondem ao topo e base de uma colina. A estrutura do perfil difere dos anteriores por apre- sentar horizonte bauxítico incipiente, crosta ferruginosa colunar mais espessa (Fig. 2) e é marcante a ausência de horizonte desmantelado sobre a crosta. O saprólito preserva parcialmente a laminação do protólito e níveis de "pedras-de-ferro" constituídos por areia quartzosa muito fina cimentada por óxi-hidróxidos de Fe são freqüentes. É um horizonte rico em caulinita (71\%) intercalado por níveis quartzosos (95\%). A presença de muscovita (7\%) e illita (3\%) no saprólito diferencia este perfil dos do Pitinga (Tab. 3). O espesso horizonte mosqueado (6 m) é uma característica marcante deste perfil. É constituído, em média, por mais de $80 \%$ de caulinita e apresenta porções ferruginosas e aluminosas que se tornam mais endurecidas em direção ao topo para formar a crosta. Esta tem $4 \mathrm{~m}$ de espessura, é ferro-aluminosa, vermelha com porções cinza escura, colunar a protonodular incipiente e cortada por fissuras preenchidas por argila caulinítica $(<88 \%)$. É composta por hematita + goethita (52\%), gibbsita $(<33 \%)$ e quartzo $(<15 \%)$. A gibbsita forma agregados rosados na superfície das colunas ferruginosas (Fig. 3), especialmente na base da crosta. Nas encostas, a crosta está ausente e o solo assenta-se sobre o topo do mosqueado. O solo (6 $\mathrm{m})$, que também recobre a crosta no topo do platô, é mais espesso que nos perfis 1 e 2 e tem contato brusco tanto com a crosta quanto com o mosqueado (perfil truncado). É argilo-arenoso, amarelo-avermelhado a cinza no topo e composto por matriz caulinítica $(89 \%)$ e fragmentos gibbsíticos alongados $(2 \mathrm{~cm})$ e hematíticos arredondados $(1 \mathrm{~cm})$, que desaparecem gradativamente para o topo.

Composição química Este perfil, assim como os demais, é composto principalmente de $\mathrm{Al}_{2} \mathrm{O}_{3}, \mathrm{Fe}_{2} \mathrm{O}_{3}$ e $\mathrm{SiO}_{2}$ (Fig. 4) Os teores de $\mathrm{Al}_{2} \mathrm{O}_{3}$ são menores que nos perfis 1 e 2, $\mathrm{SiO}_{2}$ maiores, enquanto os de $\mathrm{Fe}_{2} \mathrm{O}_{3}$ equivalentes. Assim como nos perfis 1 e 2, o $\mathrm{Fe}_{2} \mathrm{O}_{3}(51 \%)$ ocorre como hematita e goethita na crosta (colunar e protonodular), entretanto, nesta, $\mathrm{Al}_{2} \mathrm{O}_{3}$ e $\mathrm{SiO}_{2}$ estão relacionados sobretudo a caulinita, exceto nos fragmentos gibbsíticos alongados do horizonte desmantelado, onde $\mathrm{Al}_{2} \mathrm{O}_{3}$ predomina com $58 \%$ e o $\mathrm{SiO}_{2}$ não atinge $7 \%$ (Tab. 4). Os teores de $\mathrm{TiO}_{2}$ são os mesmos nos três perfis, entretanto, $\mathrm{MgO}$ e $\mathrm{K}_{2} \mathrm{O}$ são mais elevados neste (fácies argilosa do saprólito) em conseqüência da presença de illita e muscovita. Não há dados sobre a composição química da rocha-mãe desse perfil.

Elementos-traço A maioria ( $\mathrm{Ba}, \mathrm{Y}, \mathrm{Sr}, \mathrm{Rb}, \mathrm{Sc}, \mathrm{Pb}, \mathrm{Ni}$, $\mathrm{Cu}, \mathrm{Co}, \mathrm{Mn}$ e $\mathrm{Zn}$ ) encontra-se em teores abaixo da média crustal e somente Zr, Hf, Hf, Ta, Th, Nb e Ga acima (Tab. 5). As maiores variações ocorrem nas fácies arenosa do saprólito, geralmente com baixo conteúdo de traços, e na argilosa, mais abundante em Ba, Sr e V (Fig. 8). Os elementos-traço ocorrem, de modo geral, em teores inferiores aos dos perfis 1 e 2 , pois derivam de rochas sedimentares normalmente pobres nesses elementos. Os mais abundantes na crosta desse perfil são $\operatorname{Zr}(220$ - 1500 ppm), V (5 - $560 \mathrm{ppm})$ e Mn (10 - $450 \mathrm{ppm})$, os menos $\mathrm{Ba}, \mathrm{Cu}, \mathrm{Co}, \mathrm{Mo}, \mathrm{Ni}, \mathrm{Pb}, \mathrm{As}, \mathrm{Sc}, \mathrm{Y}, \mathrm{Nb}$ e U $(<20$ ppm), enquanto $\mathrm{Ga}, \mathrm{Cr}$ e $\mathrm{Zn}$ ocorrem em teores intermediários. O conteúdo de ETR é superior ao do perfil 2, mas inferior 

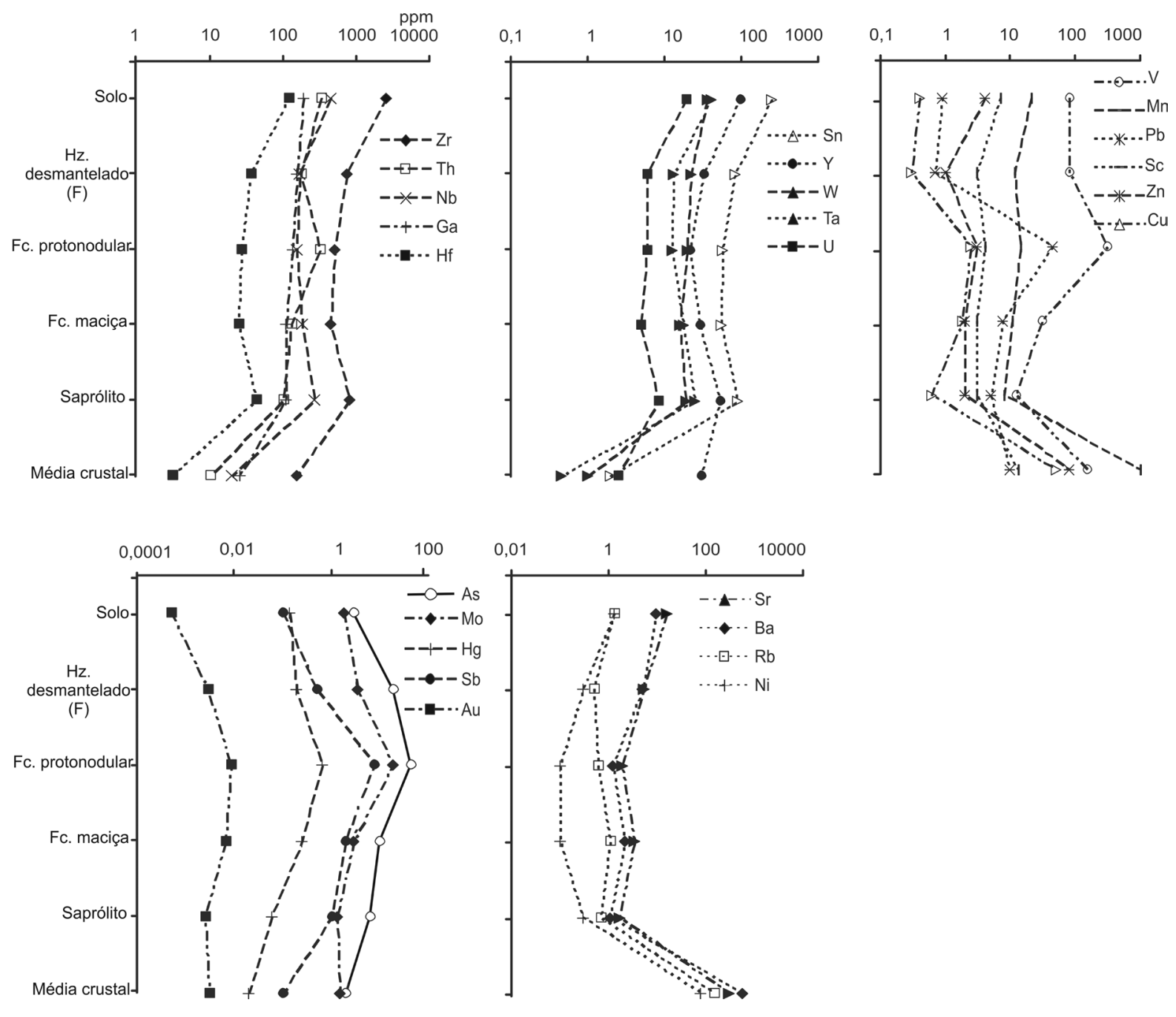

Figura 7 - Distribuição dos elementos-traço no perfil 2. Os valores dos elementos-traços da matriz do horizonte desmantelado estão na tabela 5 . Hz-horizonte; $F c$-fácies; $F$-fragmentos.

ao do perfil 1. Dentre os ETR, apenas Ce e La ocorrem acima da média crustal, enquanto os demais são equivalentes a ela (Tab. 6). Predominam na fácies argilosa do saprólito $(\Sigma \mathrm{ETR}=719 \mathrm{ppm})$ e são escassos na arenosa $(\Sigma \mathrm{ETR}=77 \mathrm{ppm})$, com diminuição dos teores para o topo. Os ETRL estão enriquecidos em relação aos ETRP, como ocorre no perfil 1 (Fig. 6), sendo a razão $\mathrm{La}_{\mathrm{N}} / \mathrm{Lu}_{\mathrm{N}}$ levemente mais acentuada neste perfil $(8,04-18,1)$ com tendência a diminuir da base para o topo.

TRATAMENTO ESTATÍSTICO Neste estudo não foi considerada a crosta do perfil 3 pois somente alguns elementos-traço foram analisados. Os resultados mostram que $57,15 \%$ da variância total das cargas dos elementos químicos considerados neste estudo $\left(\mathrm{Fe}_{2} \mathrm{O}_{3}\right.$, $\mathrm{Al}_{2} \mathrm{O}_{3}, \mathrm{SiO}_{2}, \mathrm{~K}_{2} \mathrm{O}, \mathrm{TiO}_{2} \mathrm{Zr}, \mathrm{Ba}, \mathrm{Nb}, \mathrm{Ga}, \mathrm{Y}, \mathrm{Hf}, \mathrm{Sr}, \mathrm{Th}$, $\mathrm{V}, \mathrm{Sn}, \mathrm{Pb}, \mathrm{Ta}$, As e ETR) pode ser explicada por fatores relacionados às componentes principais $1(33,85 \%)$ e $2(23,3 \%)$. Com a extração dos 10 fatores mais significativos é alcançada $99,7 \%$ da representatividade dos resultados. A análise de componentes principais (ACP) identificou três associações geoquímicas (Fig. 9a) que podem estar relacionadas a três grupos de amostras (Fig. 9b). A associação geoquímica $1\left(\mathrm{SiO}_{2}, \mathrm{Al}_{2} \mathrm{O}_{3}, \mathrm{~K} 2 \mathrm{O}, \mathrm{Ba}\right.$, Sr e ETRL) representa, principalmente a composição química do saprólito, mosqueado (perfil 3) e de parte das amostras da crosta (perfil 1), designadas de grupo 1 , onde ocorrem como caulinita, gibbsita (perfis 1 e 2), illita, muscovita e quartzo (perfil 3). A associação 2 (V, $\mathrm{Pb}, \mathrm{Fe}_{2} \mathrm{O}_{3}$ e $\mathrm{As}$ ) representa os que se concentram principalmente na crosta laterítica (perfis 1 e 2), rica em óxi-hidróxidos de ferro (hematita e goethita), e também nos fragmentos gibbsíticos com hematita (perfil 2) que compõem o grupo 2 (crosta e fragmentos). A associação 3 (Ga, Th, Ta, Sn, Nb, Hf, Zr, Y, Ti, ETRP) reflete principalmente a composição do solo e matriz (grupo 3), onde ocorrem em teores mais elevados e estão relacionados aos resistatos (zircão, columbita, thorita, xenotima etc.) acumulados residualmente e ao anatásio, $\mathrm{TiO}_{2}$ (Fig. 9a).

INTERPRETAÇÃO DOS RESULTADOS E CONCLUSÕES A potencialidade econômica das rochas do embasamento da Amazônia brasileira como geradoras de bauxitas já havia sido apontada por Costa et al. (1988). Outros estudos no NE do Amazonas (Horbe et al. 2001) constataram também potencial nas ro- 

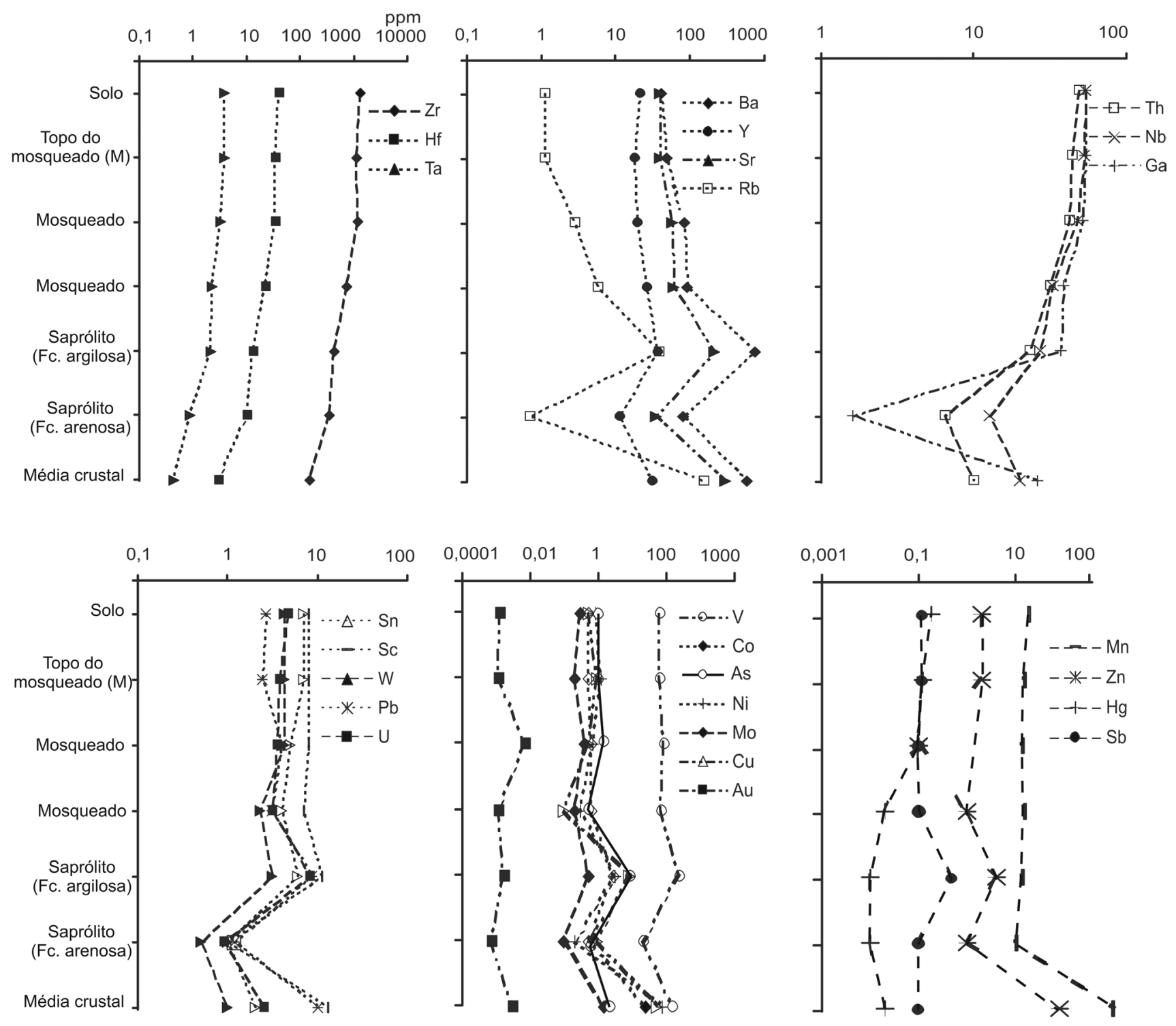

Figura 8 - Distribuição dos elementos-traço no perfil 3. Os valores dos elementos-traços dos fragmentos do topo do mosqueado estão na tabela 5. Fc-fácies; Hz-horizonte; HzM-horizonte mosqueado; M-matriz.

chas sedimentares paleozóicas. Essas duas informações transformaram a porção nordeste do Amazonas em uma fronteira a ser pesquisada para esse bem mineral. Este trabalho, além de confirmar esse potencial, mostra que apesar dos protólitos serem distintos, as características da bauxita gerada pelas rochas ígneas do Pitinga são similares as de Paragominas, Trombetas/Nhamundá e Juruti no Pará (Boulangé \& Carvalho 1997; Kotschoubey et al. 1997, Lucas 1997, Kotschoubey et al. 2005b). Os teores de $\mathrm{Al}_{2} \mathrm{O}_{3}$ entre 50 e $60 \%, \mathrm{SiO}_{2}$ entre 1 e $4 \%$, $\mathrm{Fe}_{2} \mathrm{O}_{3}$ entre 1 e $7 \%$ e TiO 2 próximo a $2 \%$ atestam a qualidade industrial da bauxita do Pitinga, conforme especificação de Ramos (1982) $\left(\mathrm{Al}_{2} \mathrm{O}_{3} 50-60 \%, \mathrm{SiO}_{2}\right.$ reativa $<5 \%, \mathrm{Fe}_{2} \mathrm{O}_{3}<3,75 \%$ e $<4 \%$ de $\mathrm{TiO}_{2}$ ).

A crosta bauxítica derivada das rochas vulcânicas (perfil 1) é mais espessa que a sobre granitos (perfil 2), estão dentro dos padrões encontrados no leste da Amazônia. A maior espessura da crosta sobre as vulcâ- nicas se deve a textura afanítica da rocha em relação a dos granitos e também pela tendência de parte do $\mathrm{SiO}_{2}$ ocorrer como vidro nesse tipo de rocha, o que facilita a transformação mineralógica.

A nodulação incipiente logo acima do contato entre o saprólito e a crosta, os inúmeros pisólitos ferruginosos com borda concêntrica de gibbsita e a presença de manchas amareladas goethíticas, principalmente na parte inferior da crosta dos perfis 1 e 2 , sugerem que a variedade de fácies das crostas desses perfis resultam da evolução progressiva do intemperismo com intensa percolação de fluidos transportando ferro e alumínio. Um fato relevante, também observado nos perfis 1 e 2 , é a fácies protonodular na porção intermediária da crosta ser o material mais ferruginoso. Essa maior ferruginização da porção intermediária da crosta também foi observada nas bauxitas desenvolvidas sobre a Formação Itapecuru (Kotschoubey et al. 2005a) e parece 

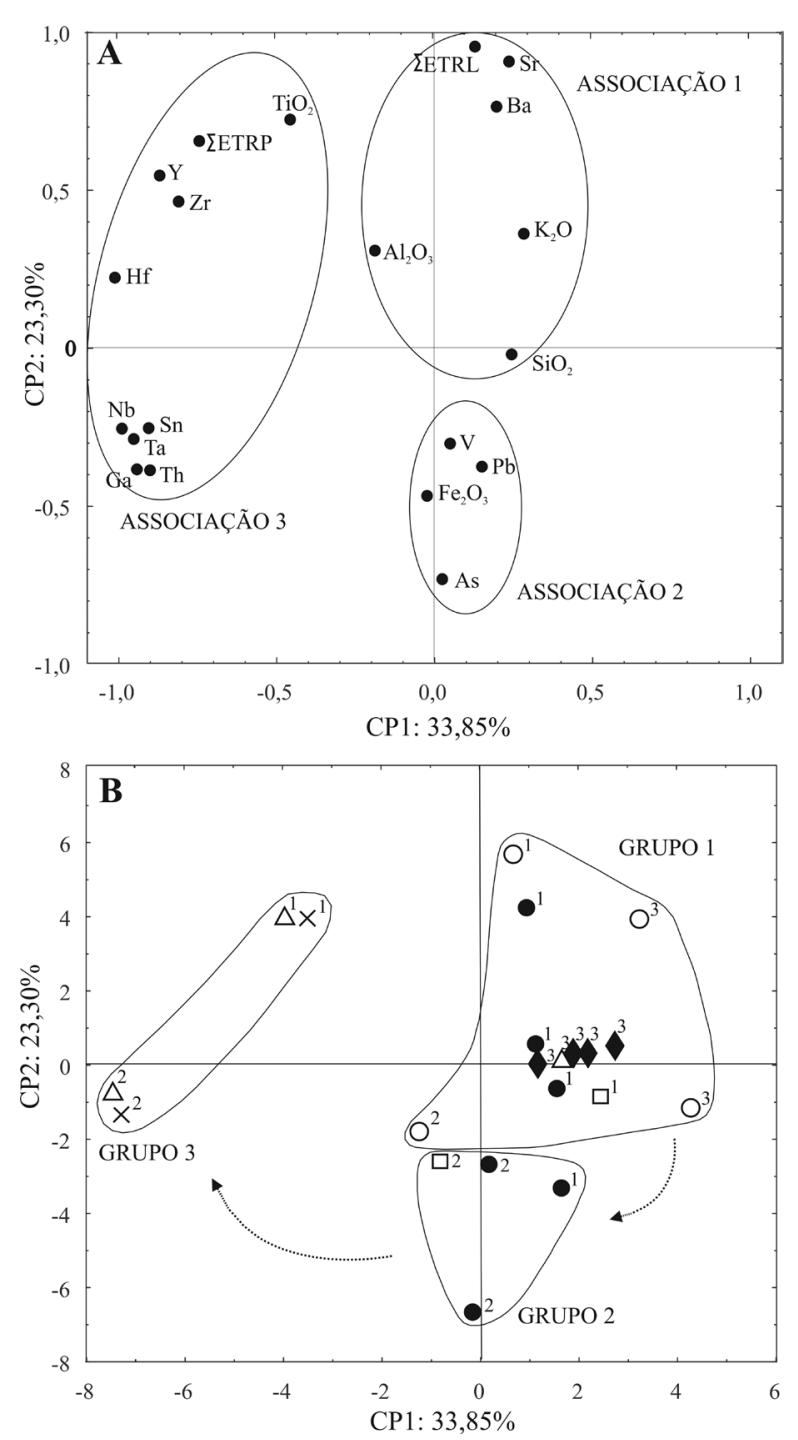

Figura 9 - Análises de componente principal. (a) distribuição dos elementos e (b) amostras no planofatorial (CP1 X PC2). O - saprólito; - horizonte mosqueado; - crosta; $\square$ - fragmentos do horizonte desmantelado; $\times$ - matriz do horizonte desmantelado; $\Delta$ - solo. 1 - perfil 1 sobre vulcânicas; 2 - perfil 2 sobre granitos; 3 - perfil 3 sobre rochas sedimentares.

ser uma característica comum nesse tipo de material na Amazônia.

Apesar da ausência de horizonte mosqueado nos perfis 1 e 2, o que indica condições hidrolíticas severas no desenvolvimento das crostas, Costa et al. (1988) encontraram esse horizonte nos perfis desenvolvidos a partir das rochas vulcânicas a sul da área estudada. Isso sinaliza variações regionais nas condições de lixiviação e justifica a ausência de horizontes bauxíticos em outras porções da área. Fato similar foi constatado em perfis sobre outros tipos de rochas (Aleva 1979, Soler \& Lasaga 2000, Lopes \& Carvalho 1990). Com base no exposto, pode-se considerar que a bauxitização incipiente observada no perfil 3 não significa que em outros locais da região não possa ocorrer horizonte bauxítico mais espesso sobre a Formação Prosperança, contudo a pequena exposição areal dessa unidade (Fig. 1) pode ser um fator limitante para o seu melhor desenvolvimento e preservação quando comparado com os perfis sobre as rochas ígneas. A variedade de protólitos submetidos aos agentes controladores do intemperismo como paleoclima, vegetação, relevo e condições de drenagem, com desenvolvimento de bauxita, é conseqüência do intemperismo ser de escala regional. Isto explica também a ocorrência de espessos horizontes bauxíticos sobre rochas de uma mesma unidade em uma área e sua ausência em locais relativamente próximos.

Assim como em outros locais da Amazônia, o intemperismo no NE do Amazonas gerou crostas aluminosas e ferruginosas in situ, uma vez que mostram forte correlação entre seus elementos químicos e os materiais de cada horizonte, especialmente os ETR. A semelhança química entre o saprólito dos perfis 1 e 2 com a parte aluminosa da respectiva crosta e os fragmentos do perfil 1 é conseqüência da intensa lixiviação que afeta a rocha mãe e neoforma gibbsita. $\mathrm{O}$ teor mais elevado de $\mathrm{SiO}_{2}$ no solo do perfil 3 que nos demais agrupa este horizonte ao saprólito e mosqueado dos perfis 1 e 2. Os teores de $\mathrm{TiO}_{2}$ e $\mathrm{P}_{2} \mathrm{O}_{5}$ na crosta do perfil 3 são similares aos obtidos por Kotschoubey et al. (2005a) nas bauxitas formadas a partir das rochas sedimentares da Formação Itapecuru. O mesmo ocorre, em média, com $\mathrm{Zr}, \mathrm{Ba}, \mathrm{Sr}, \mathrm{V}, \mathrm{Nb}, \mathrm{Ga}, \mathrm{Y}, \mathrm{Hf}$, Th e ETR.

Com o avanço do intemperismo, especialmente $\mathrm{SiO}_{2}$ e álcalis foram lixiviados dos aluminossilicatos, enquanto $\mathrm{V}, \mathrm{Pb}, \mathrm{Fe}_{2} \mathrm{O}_{3}$ e As concentraram-se na crosta e seus fragmentos ricos em óxi-hidróxidos de ferro (hematita e goethita), conforme aponta o modelo proposto por diversos pesquisadores (Kotschoubey \& Truckenbrodt 1981, Kronberg et al. 1982, Truckenbrodt et al. 1982, Costa 1997, Tardy \& Roquin 1998, Kotschoubey et al. 2005b entre outros). A associação $\mathrm{Ga}, \mathrm{Th}, \mathrm{Ta}, \mathrm{Sn}, \mathrm{Nb}, \mathrm{Hf}, \mathrm{Zr}, \mathrm{Y}$, Ti e ETRP indica que as rochas ígneas, inicialmente com teores elevados nesses elementos, os concentraram ainda mais durante o intemperismo, especialmente na matriz argilosa do horizonte desmantelado e no solo dos perfis 1 e 2. Os conteúdos mais elevados nesses elementos no perfil $2 \mathrm{em}$ relação ao perfil 3 é conseqüência da intensa especialização dos granitos do Pitinga para $\mathrm{Sn}, \mathrm{Zr}, \mathrm{Nb}, \mathrm{Y}$ e ETR (Horbe \& Costa 1999, Costi et al. 2002).

As idades da lateritização na Amazônia ainda não foram plenamente estabelecidas, as mais precisas resultam de dados geocronológicos em crostas lateríticas manganesíferas de Carajás (Vasconcelos et al. 1994, Ruffet et al. 1996, Costa et al. 2005) e paleomagnéticos em crostas ferruginosas e aluminosas da Guiana Francesa e Suriname (Théveniaut \& Freyssinet 1999 e 2002). Elas indicam formação entre 65 e $70 \mathrm{Ma}$ (Cretáceo SuperiorPaleoceno) e marcariam o primeiro episódio de bauxitização. Essa informação indica que o desenvolvimento de crostas lateríticas sobre diversos protólitos iniciou no Paleógeno e que o norte do Amazonas esteve exposto a esse processo, assim como grande parte da Amazônia 
(Boulangé \& Carvalho 1997, Costa 1997, Lucas 1997, Kotschoubey et al. 1997 e 2005b). Atualmente a região está dissecada pelos processos erosivos, é caracterizada por platôs mais altos e extensos sobre as rochas do embasamento, enquanto as unidades mais jovens, com platôs topograficamente mais baixos e menores, estão em sua maior parte sustentados por perfis truncados.
Agradecimentos Os autores agradecem ao Grupo Paranapanema S/A que permitiu a pesquisa na mina do Pitinga, a Fundação de Amparo à Pesquisa do Estado do Amazonas (FAPEAM) que concedeu bolsa de mestrado ao primeiro autor e ao CNPq (processo $\mathrm{n}^{\circ}$. 472426/2004-4) responsável pelo auxílio financeiro à pesquisa.

\section{Referências}

Aleva G.J.J. 1979. Bauxitic and other duricrusts in Suriname: a review. Geol. Mijnbouw, 58 (3):321-336.

Anand R.R. \& Butt C.R.M. 2003. Distribution and evolution of 'laterites' and lateritic weathering profiles, Darling Range, Western Australia. Australian Geomechanics, 38:41-58.

Anand R.R. \& Gilkes R.J. 1987. The association of maghemite and corundum in Darling Range laterites, Western Australia. Australian Journal of Soil Research, 35:303-11.

Angélica R.S. \& Costa M.L. 1991. Associações geoquímicas nos lateritos superficiais do Complexo de Maicuru, Estado do Pará. Geochimica Brasiliensis, 5:101-115.

Angélica R.S. \& Costa M.L. 1993. Geochemistry of rareearth elements in surface lateritic rocks and soils from the Maicuru Complex, Pará, Brazil. Jour. Geochem. Explor., 47:165-182.

Beissner H., Carvalho A., Lopes L.M., Valeton I. 1997. The Cataguazes Bauxite Deposit. In: Carvalho A., Boulangé B., Melfi A.J., Lucas Y. (eds.) Brazilian Bauxites. São Paulo, USP/FAPESP/ORSTOM, p. 195-208.

Boulangé B. \& Carvalho A. 1997. The bauxite of Porto Trombetas. In: Carvalho A., Boulangé B., Melfi A.J., Lucas Y. (eds.) Brazilian Bauxites. São Paulo, USP/FAPESP/ORSTOM, p. 55-73.

Costa M.L. 1991. Aspectos geológicos dos lateritos da Amazônia. Rev. Bras. Geoc., 21(2):146-160.

Costa M.L. 1997. Lateritization as a major process of ore deposit formation in the Amazon region. Explor. Mining Geol., 6:79-104.

Costa M.L., Angélica R.S., Costa N.C. 1999. The geochemical association $\mathrm{Au}-\mathrm{As}-\mathrm{B}-\mathrm{W}-\mathrm{Cu}-\mathrm{Sn}$ in latosol, colluvium, lateritic iron crust and gossan in Carajás, Brazil: its importance for identification of primary ore. Jour. Geochem. Explor., 67:33-49.

Costa M.L. \& Araújo E.S. 1996. Application of multi-element geochemistry in Au-phosphate-bearing lateritic crust for identification of their parent rocks. Jour. Geochem. Explor., 57:257-272.

Costa M.L., Costa J.A.V., Angélica R.S. 1993. Gold-bearing bauxitic laterite in a tropical rain forest climate: Cassiporé, Amapá, Brazil. Chron. Rech. Min., 510:41-51.

Costa M.L., Fernandes O.J.C., Requelme M.E.R. 2005. O depósito de manganês do Azul, Carajás: estratigrafia, mineralogia, geoquímica e evolução geológica. In: Marini O.J., Queiroz E.T., Ramos B.V. (eds.) Caracterização de depósitos minerais em distritos mineiros da Amazônia. Brasília, DNPM-CT/Mineral-ADIMB, p. 227-333.

Costa M.L., Horbe M.A., Horbe A.M.C., Teixeira J.T., Costa
W.A.M. 1988. A região laterítica bauxítica do PitingaAM. In: SBG, Congr. Bras. Geol., 35, Belém, Resumos, 1:22-26.

Costi H.T., Dall'agnol R., Borges R.M.K., Minuzzi O.R.R., Teixeira J.T. 2002. Tin-Bearing Sodic Episyenites Associated with the Proterozoic, A-type Água Boa Granite, Pitinga Mine, Amazônian Craton, Brazil. Gondwana Reserarch, 5(2):435-451.

Costi H.T., Dall'agnol R., Moura C.A.V. 2000. Geology and $\mathrm{Pb}-\mathrm{Pb}$ geochronology of Paleoproterozoic volcanic and granitic rocks of Pitinga Province, Amazonian craton, Northern Brazil. Inter. Geol. Rev., 43:832-849.

CPRM 2000. Programas Levantamentos Geológicos Básicos do Brasil. Caracaraí, Folhas NA.20-Z-B e NA.20-Z-D inteiras e parte das folhas NA20-Z-A, NA-21-Y-C e NA.21$Y$ - $A$. Estado de Roraima. Brasília, escala 1:500.000.

CPRM 2001. Excursão científica no trecho Manaus - Boa Vista. Manaus, Guia de Excursão, Divulgação Interna, CPRM, [s.ident], 99p.

Cunha P.R.C., Gonzaga F.G., Coutinho L.F.C., Feijó F.J. 1994. Bacia do Amazonas. PETROBRÁS, Bol. Geoc., 8:47-55.

Davy R. 1979. A study of laterite profiles in relation to bedrock in the Darling Range, near Perth, W.A. Geological Survey of Western Australia, Report 8, 87p.

Dennen W.H. \& Norton H.A. 1977. Geology and geochemistry of bauxite deposits in the lower Amazon basin. Econ. Geol., 72:82-89.

Fernandes Filho L.A., Costa M.L., Costa J.B.S. 1997. Registros neotectônicos nos lateritos de Manaus. Rev. Geoc., 16(1):9-32.

Grubb P.L.C. 1979. Genesis of bauxite deposits in the lower Amazon basin and Guianas coastal plain. Econ. Geol., 74:735-750.

Guimarães D. \& Coelho T.S. 1945. Bauxita do Morro do Cruzeiro, Ouro Preto, MG. Boletim Divisão de Fomento da Produção Mineral, DNPM, 67:1-40.

Hickmann A.H., Smurthwaite A.J., Brown I.M., Davy R. 1992. Bauxite mineralization in the Darling Range, Western Autralia. Geological Survey of Western Australia, Report 33.

Horbe A.M.C. \& Costa M.L. 1999. Geochemical evolution of a lateritic $\mathrm{Sn}-\mathrm{Zr}$-Th-Nb-Y-REE-bearing ore body derived from apogranite: the case of Pitinga, Amazonas Brasil. Jour. Geochem. Explor., 66:339-351.

Horbe A.M.C, Nogueira A.C.R., Horbe M.A., Costa, M.L., Suguio K. 2001. A laterização na gênese das superfícies de aplainamento da região de Presidente Figueiredo, Balbina, nordeste do Amazonas. In: Reis N., Monteiro, 
M.A. (Org.) Contribuições à Geologia da Amazônia. Manaus, vol. 2, p.148-176.

Kotschoubey B., Calaf J.M.C., Lobato A.C.C., Leite A.S., Azevedo C.H.D. 2005a. Caracterização e gênese dos depósitos de bauxita da Província Bauxitífera de Paragominas, noroeste da bacia do Grajaú, nordeste do Pará/ oeste do Maranhão. In: Marini O.J., Queiroz E.T., Ramos B.V. (eds.) Caracterização de depósitos minerais em distritos mineiros da Amazônia. Brasília, DNPMCT/Mineral-ADIMB, p. 691-782.

Kotschoubey B. \& Truckenbrodt W. 1981. Evolução poligenética das bauxitas do distrito de Paragominas - Açailândia (estados do Pará e Maranhão). Rev. Bras. Geoc., 11:193-202.

Kotschoubey B., Truckenbrodt W., Calaf J.M.C. 2005b. Evolução Geológica da porção meridional da província bauxitífera de Paragominas durante o Neógeno/ Pleistoceno (nordeste da Bacia do Grajaú, nordeste do Pará e extremo oeste de Maranhão. Rev. Bras. Geoc., 35(2):263-272.

Kotschoubey B., Truckenbrodt W., Heironimous B. 1997. Bauxite Deposits of Paragominas. In: Carvalho A., Boulangé B., Melfi A.J., Lucas Y. (eds.) Brazilian Bauxites. São Paulo, USP/FAPESP/ORSTOM, p.75-116.

Kronberg B.I., Cuoston J.F., Stilianidi Filho B., Fyfe W.S., Nash R.A., Sugden D. 1979. Minor element geochemistry of the Paragominas bauxite, Brazil. Econ. Geol., 74:1869-1875.

Kronberg B.I., Fife W.S., Mckinnon B.J., Couston J.F.C., Stilianidi Filho B., Nash R.A. 1982. Model for bauxite formation: Paragominas (Brasil). Chem. Geol., 35:311320.

Lenharo S.L.R., Pollard P.J., Born H. 2000. Matrix rock texture in the Pitinga topaz granite, Amazonas, Brazil. Rev. Bras. Geoc., 30:238-241.

Lenharo S.R.L., Pollard P.J., Born H. 2003. Petrology and textural evolution of granites associated with tin and rare-metals mineralization at the Pitinga mine, Amazonas, Brazil. Lithos, 66:37-61.

Lopes L.M. \& Carvalho A. 1990. Gênese da bauxita de Mirai, MG. Rev. Bras. Geoc., 19(4):462-469.

Lucas Y. 1997. The Bauxite of Juruti. In: Carvalho A., Boulangé B., Melfi A.J., Lucas Y. (eds.) Brazilian Bauxites. São Paulo, USP/FAPESP/ORSTOM, p.107-133.

Mutakyahwa M.K.D., Ikingura J.R., Mruma A.H. 2003. Geology and geochemistry of bauxite in Lushoto district, Usambara Montains, Tanzania. Journal of African Earth Science, 36:357-369.

RADAMBRASIL. 1978. Projeto RADAMBRASIL, Folha AS-20, Manaus. Rio de Janeiro, DNPM/MME, 567p.
Ramos C.R. 1982. Perfil analítico do alumínio. Brasília, DNPM, Boletim 55, 152p.

Rose A.W., Hawkes H.E., Webb J.S. 1979. Geochemistry in mineral exploration. 2ed., New York, Academy Press, $657 \mathrm{p}$.

Ruffet G., Innocent C., Michard A., Feraud G., Beauvais A., Nahon D., Hamelin B. 1996. A geochronological ${ }^{40} \mathrm{Ar} /{ }^{39} \mathrm{Ar}$ and ${ }^{87} \mathrm{Rb} /{ }^{87} \mathrm{Sr}$ study of K-Mn oxides from the weathering of Azul, Brazil. Geochim. Cosmochim. Acta, 60:2219-2232.

Sadleir S.B. \& Gilkes R.J. 1976. Development of bauxite in relation to parent material near Jarrahdale, Western Australia. Journal of the Geological Society of Australia, 23:333-44.

Schulmann A., Carvalho A., Valeton I. 1997. Bauxite of Poços de Caldas. In: Carvalho A., Boulangé B., Melfi A.J., Lucas Y. (eds.) Brazilian Bauxites. São Paulo, USP/FAPESP/ORSTOM, p. 229-254.

Soler J.M. \& Lasaga A.C. 2000. The Los Pijiguaos bauxite deposit (Venezuela): A compilation of field data and implications for the bauxitization process. Journal of South American Earth Sciences, 13:47-65

Tardy Y. \& Roquin C. 1998. Derive des continents, paleoclimats et altérations tropicales. BRGM, Orléans, France, $473 p$.

Taylor S.R. 1964. The abundance of chemical elements in the continental crust - a new table. Geochim. Cosmochim. Acta, 38:1415-1433.

Théveniaut H. \& Freyssinet Ph. 1999. Paleomagnetism applied to laterítica profiles to assess saprolite and duricrust formation processes: the example of the Mont Baduel profile (French Guiana). Paleogeogr., Paleoclim., Paleoeco., 148:209-231.

Théveniaut H. \& Freyssinet Ph. 2002. Timing of lateritization of the Guiana Shield: synthesis of paleomagnetic results from French Guiana and Suriname. Paleogeogr., Paleoclim., Paleoeco., 178:91-117.

Truckenbrodt W., Kotschoubey B., Góes A.M. 1982. Considerações a respeito da idade das bauxitas na parte leste da região Amazônica. In: SBG/Norte, Simp. Geol. Amaz., 1, Anais, p. 201-209.

Vasconcelos P.M., Renne P.R., Brimhall G.H., Becker T.A. 1994. Direct dating of weathering phenomena by ${ }^{40} \mathrm{Ar} /{ }^{39} \mathrm{Ar}$ and $\mathrm{K}-\mathrm{Ar}$ analysis of supergene K-Mn oxides. Geochim. Cosmochim. Acta, 58:1635-1665.

Manuscrito ID 10528 Submetido em 12 de fevereiro de 2008 Aceito em 20 de junho de 2008 Sistema eletrônico de submissão 